NBER WORKING PAPER SERIES

\title{
AN EXPERIMENTAL COMPARISON OF CARBON PRICING UNDER UNCERTAINTY IN ELECTRICITY MARKETS
}

\author{
Trevor L. Davis \\ Mark C. Thurber \\ Frank A. Wolak \\ Working Paper 27260 \\ http://www.nber.org/papers/w27260 \\ NATIONAL BUREAU OF ECONOMIC RESEARCH \\ 1050 Massachusetts Avenue \\ Cambridge, MA 02138 \\ May 2020
}

The authors would like to thank staff and students at the Program on Energy and Sustainable Development as well as Sunny Wang, Arpita Kalra, and Leigh Johnson for their help in developing and running these experiments during the Energy@Stanford \& SLAC 2016 and 2017 Conferences hosted by the Precourt Institute for Energy. We gratefully acknowledge funding support from the William and Flora Hewlett Foundation and from the Office of the Vice Provost for Graduate Education at Stanford. The views expressed herein are those of the authors and do not necessarily reflect the views of the National Bureau of Economic Research.

NBER working papers are circulated for discussion and comment purposes. They have not been peer-reviewed or been subject to the review by the NBER Board of Directors that accompanies official NBER publications.

(C) 2020 by Trevor L. Davis, Mark C. Thurber, and Frank A. Wolak. All rights reserved. Short sections of text, not to exceed two paragraphs, may be quoted without explicit permission provided that full credit, including ( $)$ notice, is given to the source. 
An Experimental Comparison of Carbon Pricing Under Uncertainty in Electricity Markets Trevor L. Davis, Mark C. Thurber, and Frank A. Wolak NBER Working Paper No. 27260

May 2020

JEL No. Q4,Q52,Q54

\begin{abstract}
$\underline{\text { ABSTRACT }}$
We report on an economic experiment that compares outcomes in electricity markets subject to carbon-tax and cap-and-trade policies. Under conditions of uncertainty, price-based and quantitybased policy instruments cannot be truly equivalent, so we compared three matched carbon-tax/ cap-and-trade pairs with equivalent emissions targets, mean emissions, and mean carbon prices, respectively. Across these matched pairs, the cap-and-trade mechanism produced much higher wholesale electricity prices $(38.5 \%$ to $52.6 \%$ higher) and lower total electricity production $(2.5 \%$ to $4.0 \%$ lower) than the "equivalent" carbon tax, without any lower carbon emissions. Market participants who forecast a lower price of carbon in the cap-and-trade games ran their units more than those who forecast a higher price of carbon, which caused emissions from the dirtiest generating units (Coal and Gas Peakers) to be significantly higher (15.2\% to $33.0 \%$ ) than in the carbon tax games. These merit order "mistakes" in the cap-and-trade games suggest an important advantage of the carbon tax as policy: namely, that the cost of carbon can treated by firms as a known input to production.
\end{abstract}

Trevor L. Davis

Program on Energy

and Sustainable Development

Stanford University

616 Jane Stanford Way

Encina Hall East, 4th Floor

Stanford, CA 94305-6055

trevor.1.davis@gmail.com

Mark C. Thurber

Program on Energy

and Sustainable Development

Stanford University

Encina Hall East E412

616 Serra St

Stanford, CA 94305

mthurber@stanford.edu
Frank A. Wolak

Department of Economics

Stanford University

Stanford, CA 94305-6072

and NBER

wolak@zia.stanford.edu 


\section{Introduction}

With a known demand for carbon emissions, a carbon tax and a cap-and-trade mechanism can be made equivalent. Consider Figure 1, where setting $P_{1}$ as the carbon price yields emissions $E_{1}$ for the emissions demand curve $D_{1}$. Setting a cap on carbon emissions equal to $E_{1}$ yields a price of carbon equal to $P_{1}$ for this same emissions demand curve. An analogous equivalence result holds for the demand curve $D_{2}$.

If the demand for emissions is uncertain this equivalence relationship breaks down. Figure 1 shows that setting $P_{1}$ results in either $E_{1}$ or $E_{21}$ emissions and setting a cap of $E_{1}$ yields a price of carbon of $P_{1}$ or $P_{21}$, depending on the emissions demand curve realization. Emissions demand uncertainty can result from uncertainty in electricity demand, intermittent renewable energy production, and input fossil fuel prices, among other factors. Higher

electricity demand, lower renewable energy production, or lower input fossil fuel prices all imply an outward shift of the emissions demand curve.

With an uncertain emissions demand curve, a fixed carbon price produces a distribution of emissions outcomes. Conversely, a fixed carbon cap yields a distribution of carbon prices. Setting the carbon cap equal to the expected value of the distribution of emissions from a fixed carbon tax does not yield a distribution of carbon prices that has expectation equal to the fixed carbon tax. Setting the carbon tax equal to the expected value of the distribution of carbon prices from a fixed carbon cap does not yield a distribution of carbon emissions that has expectation equal to the initial carbon cap.

Weitzman (1974) pointed out this inherent lack of equivalence between price- and quantitybased instruments of emissions control under uncertainty. However, economic theory provides no unambiguous predictions about the relative performance of an electricity supply industry with a carbon tax versus a cap-and-trade mechanism under uncertainty, and there 
are no real-world settings that allow for a direct comparison between the two mechanisms. Economic experiments therefore have the potential to increase our understanding of the determinants of the relative performance of these two emissions control mechanisms. In this paper, we describe the results of an economic experiment that compares the performance of a carbon tax and a cap-and-trade mechanism in a stylized but realistic electricity market with an uncertain demand for emissions. Electricity is a policy-relevant space in which to evaluate carbon pricing, given that the power sector (including production of electricity and heat) is responsible for approximately one-quarter of global greenhouse gas emissions (IPCC, 2014) and has been an early focus for implementation of carbon pricing programs in a number of jurisdictions.

In our experiment, we seek insights into which carbon pricing instrument achieves lowercost emissions reductions in an electricity market with realistic sources of emissions demand uncertainty. Across matched pairs of three types of "equivalent" (to be defined below) carbon tax and cap-and-trade games, we find that the cap-and-trade mechanism results in much higher wholesale electricity prices (38.5\% to $52.6 \%$ higher) and lower total electricity generation ( $2.5 \%$ to $4.0 \%$ lower) than the carbon tax, without any significant decrease in carbon emissions. Market participants that based their offers to supply electricity on a lower price of carbon in the cap-and-trade games ran their generation units more than those that based their offers on a higher price of carbon, which caused emissions from the dirtiest generating units (Coal and Gas Peakers) to be significantly higher (15.2\% to 33.0\%) than in the carbon tax games.

We also use our experiment to investigate the mechanisms that cause outcomes from a cap-and-trade policy to deviate from those observed with a carbon tax under conditions of uncertainty. For example, the collective inability of market participants to accurately 
forecast the carbon price needed to meet the cap could lead to inefficiencies in emissions mitigation. Designers of cap-and-trade systems are sometimes retroactively criticized for a failure to set the "right" level of the emissions cap, leading to carbon prices that are "too high" or "too low," but as Borenstein et al. (2019) argue and demonstrate for the case of California's cap and trade mechanism, this uncertainty about how easy or difficult a cap will be to meet is a fundamental characteristic of any cap-and-trade system. Variation in the forecasts of the carbon price by market participants, due to asymmetric information or differences in forecasting capability, could affect market efficiency. ${ }^{1}$

If compliance penalties are significant, generating companies might hedge against the risk of failing to cover their emissions (or the risk of having to acquire allowances later at a very high price) by trying to accumulate allowances early in the compliance period at high prices. Dormady (2014) raised the possibility that such a "declining price anomaly" (McAfee and Vincent, 1993) could be observed in emissions markets. High initial carbon prices would presumably be passed through into electricity market price offers, which would increase electricity prices and lower emissions, both by preferentially pushing dirty units out of the merit order and by shrinking demand. This could lead to an eventual crash in the carbon price when it became clear that emissions were trending below the carbon cap. Depending on when this crash occurred, however, average electricity prices over the compliance period could still end up being higher than under the "equivalent" tax. If risk aversion in the face of high compliance penalties causes carbon prices to diverge from underlying fundamentals,

\footnotetext{
${ }^{1}$ If market participants factor different carbon prices into their electricity market price offers due to different forecasts, this could lead to merit order "mistakes." Market participants that anticipate lower carbon prices would bid lower than those that forecast higher carbon prices, irrespective of actual differences in emissions rates and fuel and other variable costs between units. This would produce an aggregate offer curve in which units with higher marginal costs run before units with lower marginal costs, increasing the overall cost of generation and blunting the effectiveness of the cap-and-trade system at reducing emissions (Thurber and Wolak, 2013).
} 
it could erode the efficiency of the cap-and-trade system.

The carbon market could also serve as a coordination device for the exercise of market power in the electricity market. If prices are high in the carbon market, and most generating companies factor these high carbon prices into their electricity market offers, it will push up electricity market prices, benefiting all generation unit owners. ${ }^{2}$. If the existence of capand-trade mechanism somehow encourages the exercise of market power in the electricity market, we would expect different outcomes from the carbon tax case.

We find little evidence in favor of these last two explanations for the superior market efficiency properties of the carbon tax. Rather, the major source of differences in electricity market outcomes appears to be the fact that with a carbon tax, the cost of carbon is stable and known to all suppliers, similar to the price of any other input to production. In contrast, under a cap-and-trade mechanism, the price of carbon varies over the term of the carbon cap depending on what new information arrives about the demand for emissions over time, and firms need to predict the carbon price in order to make profit-maximizing bids into the electricity market. Firms may have different abilities to make these predictions as well as asymmetric information about the factors affecting carbon price. This has the potential to cause inefficiencies in the overall market, as firms that project a lower carbon price run their generating units more than firms that project a higher one, irrespective of the underlying differences in variable costs (including the cost to buy carbon allowances) between units. We find evidence in favor of this mechanism driving the difference in market outcomes between the two carbon pricing mechanisms.

The remainder of the paper proceeds as follows. Section 2 reviews previous literature on the differences between a carbon tax and a cap-and-trade mechanism and situates our

\footnotetext{
${ }^{2}$ Kolstad and Wolak (2013) present evidence of this behavior for the Southern California $N O_{x}$ emissions market
} 
experiment within this literature. Section 3 describes the experiment and the statistical methods we use to test our hypotheses about the relative performance of carbon-tax and cap-and-trade policies and about the mechanisms that explain any differences. Section 4 lays out our experimental findings, and Section 5 concludes with a discussion of the policy implications of these results.

\section{Review of the Literature Comparing Carbon Tax with Cap and Trade Under Uncertainty}

Various authors have made the observation that a carbon tax and a cap-and-trade system can in theory provide equivalent outcomes for greenhouse gas emissions when the marginal cost and marginal benefit of abatement curves are known with certainty and perfectly foreseeable into the future (Metcalf, 2009; Aldy et al., 2010; Keohane, 2009; Strand, 2013; Goulder and Schein, 2013). However, Weitzman (1974) points out that either a price-based or a quantitybased approach may be better at minimizing policy "errors" depending on the relative slopes of the marginal cost and marginal benefit curves. For the particular case of greenhouse gas emissions reduction, Newell and Pizer (2003) and Aldy et al. (2010) argue that the marginal benefits curve is likely to be flat, implying that a carbon tax would lead to lower policy errors under uncertainty.

There are many drivers of emissions demand uncertainty under a cap-and-trade mechanism in the real-world context. As Borenstein et al. (2019) demonstrate for the California cap-and-trade market, there is substantial uncertainty in emissions demand throughout the term of the mechanism. Improved information about the actual level of emissions may show that demand for allowances is higher or lower than anticipated. For example, carbon prices 
in the EU ETS dropped precipitously in the spring of 2006 when new data showed that emissions had been lower than expected, and that the allowances that had been allocated were ample to cover them (Goulder and Schein, 2013). Specific policy implementations may be uncertain in their effectiveness and durability. For example, carbon pricing programs might prompt emitters to relocate outside the region with the carbon price, causing emissions leakage. Cap-and-trade programs may be subject to the leakage mechanisms of non-additional offsets (Wara and Victor, 2008) and "reshuffling" (Borenstein et al., 2014). Carbon prices in cap-and-trade systems can tend toward extreme values (Borenstein et al., 2019), and politicians may weaken or dismantle cap-and-trade programs if prices grow too high (Luong et al., 2003; Metcalf, 2009). One can imagine many other possible shortcomings in the practical implementation of carbon pricing that could cause performance to fall short of theoretical projections.

Political and institutional considerations can also affect which carbon pricing instrument is preferred in a real-world setting. For example, taxes are administratively simpler and may create a more stable environment for investment in abatement technologies (Metcalf, 2009). They do not require the development of allowance registries and tracking of trades (Goulder and Schein, 2013). They do not require mitigation of market power that could potentially arise in a carbon market (Borenstein et al., 2014). Governments typically already have administrative capability to levy taxes, which could speed implementation (Metcalf, 2009). On the other side of the ledger, taxes are often politically unpopular. Cap-and-trade systems have the potential political advantage of keeping attention on emissions while making costs less transparent and possibly providing compensation to affected industries in the form of free allowances (Stavins, 2007; Keohane, 2009; Strand, 2013).

Economic experiments let us abstract away from these manifold practical issues of policy 
fit and regulatory uncertainty to focus only on how the inherent uncertainty in the demand for carbon emissions in a cap-and-trade mechanism causes market outcomes to diverge from the carbon tax case. As shown in Table 1, previous experiments have considered aspects of emissions pricing in electricity markets. Notably, van Koten (2015) and Wråke et al. (2010) find that efficient abatement is observed with simple, perfectly competitive markets in which experimental subjects are price takers of exogenously set emissions permit and electricity prices across several rounds of an experimental game. Dormady (2014); Godby (2000); Goeree et al. (2010); Cason and Gangadharan (2006); Stranlund et al. (2011); Grimm and Ilieva (2013); Camacho-Cuena et al. (2012) find that efficient levels of emissions abatement are not reached in games with imperfect competition in either the emissions allowance market or the electricity market. As far as we are aware, our experiment is the first to directly compare electricity market and carbon emissions outcomes under pairs of "equivalent" carbon-tax and cap-and-trade policies with an uncertain demand for carbon emissions. It also achieves new levels of richness and realism by incorporating important emissions abatement channels in electricity markets, such as merit-order shifting, demand reduction, and the ability to introduce new low-emission generating units. Specific details of the web-based energy market game we use in this experiment are described in the following section.

\section{$3 \quad$ Methodology}

\subsection{Basic experimental setup}

We designed and ran an experiment of 160 games simulating wholesale electricity markets under various "equivalent" carbon tax and cap and trade scenarios. (As discussed in Section 1, genuine equivalence between a carbon tax and a cap-and-trade system is not possible under 
conditions of uncertainty; later in this section, we describe the specific carbon-tax/cap-andtrade pairs we defined for purposes of comparison.) In each game, eight players placed price offers - one for each of the dispatchable generation units in their identical portfolios - into a wholesale electricity market that employed a uniform-price auction. Each player also owned wind generation units that produced an uncertain amount energy each period. Players could buy additional wind generation units for future periods, and in the cap-and-trade games could trade carbon allowances with other players. Each game had the potential for imperfect competition in the electricity market as well as, in games under a cap-and-trade system, imperfect competition in carbon allowance trading. The exogenous uncertainty in how much energy wind generation units would produce as well as the endogenous uncertainty about how other players in a game would act both determined the demand for carbon emissions. Players were paid at the end of the experiment in proportion to how much money the generating companies they operated earned in the games, with pay-outs that ranged from $\$ 8$ to $\$ 18 .^{3}$

The experimental games took place in September 2016 and September 2017. In each year, the game participants were 128 incoming Stanford graduate students with a stated interest in energy who took part in a week-long energy-focused conference before the start of classes. ${ }^{4}$ The games themselves were played over a period of three days at the conference, with approximately three hours of training (including two practice games) in advance of the experimental games to ensure the participants were able to act as sophisticated players.

\footnotetext{
${ }^{3}$ These dollar amounts were paid to individuals, and all games were played on an individual basis, but we grouped the student players into teams of four to encourage strategizing, discussion, and learning that they could apply in their separate individual games. The final individual payouts were then based on overall team performance, with all members of any given team receiving the same payout. Random allocation of players to games was constrained so that two players from the same team were never in the same game.

${ }^{4} 62 \%$ percent of the graduate students were from various engineering departments, $18 \%$ were business school students, and the rest were from other programs like Chemistry, Physics, Economics, etc.
} 
The games were run using custom carbon-tax and cap-and-trade scenarios created for the Energy Market Game (EMG) developed at Stanford University's Program on Energy and Sustainable Development (see Section 3.2 for a detailed description of the EMG). This experiment incorporated four electricity market periods in each game. Before each period, each of the eight players were allowed to buy up to two wind generation units and, in capand-trade games, trade carbon allowances. Following these actions, players would place price offers for each of their dispatchable generation units into the wholesale electricity market. The electricity market for that period would be run, and the players could observe the results. In cap-and-trade games, players also had a final period after the last electricity market period in which they could trade carbon allowances before non-compliance penalties were assessed on whichever gencos did not have enough carbon allowances to cover their cumulative $\mathrm{CO}_{2}$ emissions. ${ }^{5}$ The total time to run one full four-period game was approximately 23 minutes.

In each year's conference, the 128 students participated in 5 game rounds. Within each round, every student was randomly assigned to one of 16 games (8 players per game) that were run simultaneously in that round. Over the course of the 5 rounds, each student player played 2 or 3 carbon tax games and 2 or 3 cap-and-trade games.

\subsection{Description of the Energy Market Game}

The experiment described in this paper uses the web-based Energy Market Game (EMG) previously described in Thurber and Wolak (2013); Thurber et al. (2015); Davis (2019). Development of the EMG was begun at Stanford University's Program on Energy and Sustainable Development in 2013, with the goal of allowing students to play electricity market scenarios in real time in the classroom. We subsequently expanded the use of the game

\footnotetext{
${ }^{5}$ Non-compliance penalties were set at $\$ 400$ per tonne for $\mathrm{CO}_{2}$ emissions in excess of allowance holdings at the end of the final trading period.
} 
to include workshops with policymakers and regulators. The EMG is structured to allow the incorporation of new policy scenarios, power generation portfolios, and transmission network configurations as needed. Game features incorporated to date include multiple market participant types (generating company, retailer, and vertically-integrated utility), fixed-price forward contracts for electricity, financial transmission rights (FTRs), capacity markets, carbon pricing (carbon tax and cap-and-trade system), renewable energy certificates, variable fuel price (with ability to hedge prices), power plant purchase and retirement decisionmaking, and energy storage. Game scenarios are freely available for use by the public at https://energymarketgame.org/, and at any given moment, it is likely that a number of these games are running simultaneously in classes and other educational settings around the world.

Participants in this experiment placed price offers for each of their fossil fuel generating units into each of the four electricity market periods using the Energy Market Game bidding screen shown in Figure 2. Wind units are treated as non-dispatchable, "must run" resources that are automatically bid in at at a price of zero due to their zero marginal cost; they generate electricity according to the realization of the wind resource in each market period. (If players so desired, they could buy additional wind plants by means of a power capacity management screen, subject to the limitations described in Section 3.1.) Players were given the distribution of the random variable characterizing wind output, which is displayed as a histogram in Figure 3, but they did not learn the actual wind realization for a given period until after they placed their offers. Total market demand for electricity in each period was downward-sloping but fairly inelastic. The equation is Demand (in MWh) $=16,705-5 \times$ Price (in $\$ / M W h$ ). This equation was known to all players.

A key element of the game interface in this experiment was a button at the top of the 
bidding screen that allowed players to factor a carbon price of their choice into all of their electricity market price offers. This button, which could be used at any time, set the bids for each generating unit in all future periods to the marginal cost of that unit including that price of carbon. In the cap-and-trade games, this button provided a quick and easy way for players to incorporate their estimated carbon price into their electricity bids. (To avoid possible impacts on the results due to variation in the game interface, this button appeared in both carbon tax and cap-and-trade games, even though the price of carbon was explicitly known in the carbon tax game.)

After each market period was run, players could review a summary of the electricity market results in chart form, as shown in Figure 4. The market results chart included bars showing the price offers for each of the generating units, with gray and black marks on these bars showing the marginal cost of the unit for a zero carbon price and for a benchmark carbon price, respectively. This gave players some sense of the carbon prices that other players were factoring into their price offers.

In the cap-and-trade games, players could trade carbon allowances before each of the four electricity market periods and again after the final electricity market period. The trading screen allowed players to submit buy or sell offers for allowances, or they had the option of accepting offers other players had made. The trading screen showed a player's current allowance holdings as well as their cumulative emissions to that point, clearly indicating whether they were in allowance deficit or surplus.

A market statistics screen displayed cumulative carbon emissions as well as, in the capand-trade games, traded carbon prices for previous periods. This screen was particularly important in the cap-and-trade games because it let players track whether overall emissions in the market were trending over the cap, suggesting traded carbon prices were likely to be 
higher, or under the cap, suggesting traded carbon prices were likely to be lower.

\subsection{Market design}

The electricity market in the game was designed to have three important characteristics:

First, the exercise of unilateral market power in the electricity market was possible, but difficult enough to achieve that such behavior would not render the carbon market irrelevant. The concern is as follows. If each player's generation capacity was larger than the difference between electricity demand and the sum of all the other players' capacity, that would make each player pivotal, meaning they know their capacity is needed to meet demand. In such a case, we would expect players to routinely offer very high prices (possibly at or near the offer cap) to push up electricity price and the revenue they receive in the electricity market. These high prices would tend to shrink demand, which could potentially push emissions below the carbon cap - and carbon prices to zero - in most market runs.

In the games here, the total demand in each period of approximately 17,000 MWh (see Section 3.2) was significantly less than the total available generation from dispatchable units of 24,000 MWh (3,000 MWh per player for all eight players). The games also started with two wind units per player; with each wind unit having an expected hourly output of $240 \mathrm{MWh}$, this added another 3,840 MWh of expected generation from wind. The ample generation capacity relative to demand, and the fact that no player was pivotal, made the exercise of unilateral market power in the electricity market relatively difficult. Additionally, in order to prevent excessive market concentration in the wind sector, we limited new wind purchases to two units per player before each of the first three periods, for a maximum of six new wind units per player. ${ }^{6}$ Figure 5 illustrates the offer curve at two different carbon prices when all

\footnotetext{
${ }^{6}$ New wind units came online after a one-period delay.
} 
generating units bid marginal cost and there are 16 wind units in the market.

Second, there was exogenous and endogenous uncertainty in emissions, but the amount of uncertainty was sufficiently bounded that players could observe trends and develop carbon trading strategies and electricity pricing strategies to take advantage of them. Exogenous uncertainty in emissions was provided through the random variation in the output of wind generation units from period to period. The output per wind unit was randomly chosen from a normal distribution with $\mu=240 \mathrm{MWh}$ and $\sigma=96 \mathrm{MWh}$, censored to 0-960 MWh (see Figure 3), with all wind units having the same output in a given period. When the wind output was lower than expected, more thermal generation units needed to operate in the game, increasing overall emissions; when wind output was higher than expected, the opposite was true.

In test runs prior to the experiments, this level of exogenous variation proved sufficient to drive discernible trends in emissions - and, in the cap-and-trade games, carbon pricewithout being so large that last-period emissions variations would frequently wipe out any trends to that point. Because demand was identical in each of the four game periods, and because players' financial incentives encouraged them to maintain a broadly stable number of wind generation units (see below), players could reasonably track whether emissions were trending under or over the carbon emissions cap - and formulate carbon trading strategies accordingly. Endogenous uncertainty in emissions was produced by player bidding behavior in the electricity market as well as player decisions about how many wind generation units to buy. Of the two wind generation units owned by each player at the start of game, one was retired after period 1 and the second was retired after period 2. A player could buy up to two wind generation units per period, with the new generation units coming online after a one-period delay. ${ }^{7}$ Each new wind plant incurred a fixed cost of $\$ 33,600$ for each

\footnotetext{
${ }^{7}$ By purchasing new unit before period 1 and a second unit after period 2, a player could maintain two
} 
period it was online. Given this fixed cost, wind generation units were profitable if there were 16 or fewer of them, under the assumptions that wind output was exactly as forecast, all players bid marginal cost for all generating units, and a carbon price of $\$ 127$ was factored into electricity market price offers. This meant that players were incentivized, on average, to exactly replace their retiring wind units, which had the benefit of making expected emissions the same across all four periods, making it easier for players to calculate whether carbon emissions were trending under or over the cap. The average number of wind units in a game period did in fact turn out to be 16, though some periods in some games had more and others had less (see Figure 6).

Third, the electricity market included different types of generation units with stylized but realistic characteristics that would yield merit order shifts at higher carbon prices. ${ }^{8}$ This goal was achieved with the use of a simple portfolio of six thermal units, each with a different variable cost and emissions rate (see Table 2). In addition to the two original wind units plus any additional wind units that were purchased, each player operated two baseload coal-fired units (low variable cost and high emissions rate), one baseload gas-fired unit (low variable cost and low emissions rate), two different gas-fired "mid" units (medium variable cost and medium emissions rate), and one gas-fired peaker (high variable cost and high emissions rate). At higher carbon prices, the generation units with higher emissions rates are relatively more expensive to operate, which should lead to significant merit order shifts, with displacement of the baseload coal-fired generation units by gas-fired alternatives. Figure 7 illustrates the carbon prices at which merit order shifts would occur - and the effects on emissions and electricity price - if all players made price offers at marginal cost for all wind units for all four periods of the game.

${ }^{8}$ The merit order of generation units is the aggregate offer curve of units assuming all units submit offers equal to their marginal cost, including the cost of carbon. 
units and total wind generation took on different specified values.

\subsection{Equivalence of a carbon tax and cap-and-trade system}

Under perfectly competitive markets with no uncertainty, one can construct a pair of capand-trade and carbon-tax policies that yield identical carbon prices, wholesale electricity prices, and emissions. Under such conditions it is easy to create "equivalent" cap-and-trade and carbon-tax policies. However, in real wholesale electricity markets there is neither perfect competition nor perfect certainty. Therefore, as discussed in Section 1, it is not possible to construct a pair of cap-and-trade and carbon-tax policies such that there are identical carbon prices and emissions. What does it mean in such a context for a cap-and-trade policy to be equivalent to a carbon-tax policy?

Most papers consider a cap-and-trade policy to be equivalent to a carbon-tax policy when the cap-and-trade cap is equal to the expected emissions from the carbon-tax policy (Strand, 2013). In this paper we call such an equivalency an equivalent "Emissions Target". However, a cap-and-trade policy and carbon tax with equal emissions targets will likely have unequal expected carbon prices (and vice versa). To illustrate this, we simulated 250,000 carbon tax games assuming marginal cost pricing with a carbon tax of $\$ 127.00$ and no change in wind holdings from the original 16 generation units ${ }^{9}$. Because each game has different realizations of wind across the 4 periods, this leads to 250,000 different realizations of game emissions, which is shown in Figure 8. The mean emissions from these simulated carbon tax game runs was 32,697 tonnes of $\mathrm{CO}_{2}$. We then simulated 250,000 cap-and-trade games with a carbon cap of 32,697 tonnes of $\mathrm{CO}_{2}$, assuming marginal cost bidding, no change in wind holdings from the original 16 generation units, and the exact same wind realizations as in the

\footnotetext{
${ }^{9}$ With a carbon tax of $\$ 127$, marginal cost pricing, and 16 generation units it is not profitable for a genco to move to more/less wind units.
} 
previous carbon tax simulation. In each game we assume players have perfect information as to what the wind will be and they all agree on the lowest (non-zero $)^{10}$ carbon price such that emissions are (weakly) ${ }^{11}$ less than the carbon cap. Because each game has different realizations of wind, this leads to 250,000 different realizations of the carbon price needed to not exceed the carbon cap, which is shown in Figure 9. The mean of these simulated capand-trade carbon prices was $\$ 136.21$, which is $7 \%$ more than the expected $\$ 127$ carbon price of the carbon tax with the equivalent "Emissions Target". This illustrates in a concrete way that we cannot construct "equivalent" carbon tax and cap-and-trade games such that both expected emissions and expected carbon prices are the same under conditions of realistic uncertainty.

We observe that, under uncertainty, expected emissions from a given carbon cap policy may be less than the cap. To see why, consider Figure 9, which shows the histogram of carbon prices from 250,000 simulations of one of our carbon cap treatments. The distribution of cap-and-trade carbon prices is not smooth but instead concentrates probability mass at a few points corresponding to carbon prices where merit order shifts occur in our wholesale-electricity-market supply curve. At these price points, we see large and discontinuous decreases in emissions ${ }^{12}$. For simulated games with a merit-order-shifting carbon price, such discontinuous decreases in emissions can make overall emissions strictly less than the cap $^{13}$. We also observe that the distribution of carbon prices in the simulated games is not symmetric but instead has a long tail of high carbon prices, with the mean carbon price higher than the median. This explains why the average carbon price in the cap-and-trade

\footnotetext{
${ }^{10}$ In less than $0.2 \%$ of the simulations we do in fact observe a carbon price of $\$ 0$.

${ }^{11}$ In one half of the simulations are they able to find a non-zero carbon price to exactly hit the carbon cap.

${ }^{12}$ See for example Figure 7 (a), (c), (e)

${ }^{13}$ In a few rare simulations wind conditions were so strong that we also didn't reach the cap even with a carbon price of zero.
} 
game is higher than that in the carbon tax game with the equivalent "Emissions Target".

Therefore, in addition to "Emissions Target" equivalency, our simulations suggest two other kinds of equivalency that are possible between carbon tax and cap-and-trade policies. We can define "Mean Emissions" equivalency, where a given carbon tax and cap-and-trade system yield the same expected emissions, and "Mean Carbon Price" equivalency, where the two policies have equivalent expected carbon prices. For our experiment, we define six policy treatments that together encompass the range of these kinds of equivalencies: three cap-and-trade policies labelled "Cap I", "Cap II", and "Cap III", and three carbon-tax policies labelled "Tax I", "Tax II", and "Tax III" (see Tables 3 and 4). Cap I, Cap II, Tax I, and Tax II were from the 2017 conference game. Cap III and Tax III were from the 2016 conference game. The set of treatments was constructed as follows:

1. Tax I is defined as having a $\$ 127$ carbon price. In 250,000 simulated games with random wind realizations (see below), it produces average emissions of 32,697 tonnes of $\mathrm{CO}_{2}$ for the four periods.

2. Cap I sets the Tax I expected emissions of 32,697 as its cap, such that Cap I and Tax I are "Emissions Target" equivalent. We simulated 250,000 games with this cap, assuming marginal cost pricing, no change in wind holdings from the original 16 generation units, perfect foreknowledge of that game's wind realizations, and the restriction that carbon price could not be negative. For each simulated game, we determined the carbon price that would produce total emissions as close to the cap as possible without going over. The average carbon price across the simulated games was $\$ 136.21$.

3. Tax II sets $\$ 136.21$ (the average carbon price for the Cap I simulations) as its carbon price. In 250,000 simulated games, it produces average emissions of 32,552 tonnes of 
$\mathrm{CO}_{2}$

4. Cap II sets the Tax II expected emissions of 32,552 as its cap, such that Cap II and Tax II are "Emissions Target" equivalent. We used the same simulation procedure as for Cap I, finding an average carbon price across the simulated games of $\$ 140.83$.

5. Tax III is set to have a $\$ 120$ carbon price. In 250,000 simulated games with random wind realizations, it produces average emissions of 32,807 tonnes of $\mathrm{CO}_{2}$ for the four periods.

6. Cap III sets a cap of 33,152 tonnes of $\mathrm{CO}_{2}$ which leads to an expected emissions of 32,887 tonnes, such that Cap III and Tax III are "Mean Emissions" equivalent. We used the same simulation procedure as for Cap I and Cap II, finding an average carbon price across the simulated games of $\$ 123.68$.

As described above (and summarized in Table 5), Cap I and Tax I (treatment pair TI) and Cap II and Tax II (treatment pair TII) were both "Emissions Target" equivalent. Also (by design), Cap I and Tax II (treatment pair MCP) were "Mean Carbon Price" equivalent. Finally, Cap III and Tax III (treatment pair ME) were "Mean Emissions" equivalent.

\subsection{Regression methodology}

For the subset of data corresponding to any treatment pair, we can regress any variable of interest on a dummy variable indicating the carbon-tax treatment, while controlling for any relevant fixed effects. All the regressions in this paper control for the pseudo-random seed used for the wind generation of the game. Because these seeds varied by round and year of the experiment, they effectively served as Game $\times$ Round fixed effects in the TI, TII, ME, and MCP comparisons. For the regressions of logged market price, assumed carbon price, and 
generation unit plant price offer markups, we also include a Period fixed effect for the period of wholesale electrical generation within a game ${ }^{14}$. For the regressions of assumed carbon price and electricity market price offers, we include Player fixed effects. In our electricity market price offer markup regressions we include Generation Unit fixed effects. ${ }^{15}$

To estimate the magnitude of the conditional variance effect, we take the squared residuals from the mean effect regressions and regress them again on the same regressors used in the original regression: fixed effects for the variable in question and a dummy of whether we applied a carbon-tax system to that observation. The coefficient on the carbon-tax dummy variable measures how much the conditional variances differ between cap-and-trade games and carbon tax games. ${ }^{16}$

\section{Results}

\subsection{Overall observations}

Several differences between the carbon tax and the cap-and-trade games are immediately obvious from summary statistics. First and foremost, electricity prices are significantly higher in the cap-and-trade games, with significantly larger variance (Tables 6 and 7 and Figure 10). This is a function of the higher and more variable price offers players placed in

\footnotetext{
${ }^{14}$ We do not include a Period fixed effect for the ME assumed carbon price regression since in the 2016 version of the experiment we did not store assumed carbon prices for periods 1, 2, and 3

${ }^{15}$ In the offer price regressions, we exclude wind generation units, which were all automatically priced at $\$ 0$.

${ }^{16}$ To determine whether there are significant differences in the conditional variance of market outcomes between the various "equivalent" carbon pricing mechanisms, we test the variables of interest for homogeneity of variance across each "equivalent" treatment pair using Bartlett's test, Fligner-Killeen's test, Levene's test (with mean center), and Levene's test (with median center), also known as the Brown-Forsythe test of homogeneity of variances. If almost all tests reject the null hypothesis of homogeneous variances between cap-and-trade and carbon tax games, we conclude that carbon pricing policy probably has an effect on variance of the variable in question.
} 
the cap-and-trade games (Tables 8 and 9), which seem to follow from the higher and more variable carbon prices players assumed when placing these offers (Tables 10 and 11).

Players explicitly entered their "assumed carbon price" when they placed their electricity market price offers, with the following logic. In a competitive electricity market (i.e. players have no ability to exercise unilateral market power), the profit-maximizing pricing strategy is to price each unit at marginal cost including the marginal cost of carbon, which is the carbon price $\left(\$ /\right.$ tonnes of $\left.\mathrm{CO}_{2}\right)$ times the unit's emissions rate (tonnes of $\mathrm{CO}_{2} / \mathrm{MWh}$ ). To make it easy to price in this way, each player had the option, on their electricity market pricing screen, to explicitly factor a particular price of carbon into their electricity market price offers (see Section 3.2). This would update each of their generation unit offers for that period (and any future periods) to that unit's marginal cost incorporating the specified price of carbon. ${ }^{17}$ The assumed carbon price a player entered in this way - and which the game program recorded for later analysis - can reasonably be interpreted to represent that player's expectations about the carbon price. ${ }^{18}$

In the carbon tax game, the carbon price was clearly known: it was simply the tax. ${ }^{19}$ Therefore, it is unsurprising that the assumed carbon price players used for their electricity market price offers was very tightly clustered around the level of the carbon tax. In the cap-and-trade game, the assumed carbon price reflected the carbon price at which the player thought they could buy or sell carbon allowances in the allowance market. This price could vary as each game progressed, with wind realizations and other players' pricing behavior

\footnotetext{
${ }^{17}$ At the beginning of game the default "assumed carbon price" was the carbon price in the "Carbon Price Mean" column in Table 4, except for in 2016 when the initial assumed carbon price in the Cap III treatment was set to $\$ 120$ like in the Tax III treatment.

${ }^{18}$ While it is possible for a player to enter a carbon price value on the bidding screen that differs from their actual carbon price expectation - and thus from profit-maximizing behavior - we believe that the pre-game training was sufficiently thorough to discourage such behavior.

${ }^{19}$ Players were still given the option on the price offer screen to alter their assumed carbon price.
} 
causing the expected carbon price to go up or down. However, the observed distribution of assumed carbon prices was not symmetrical about the expected level of the carbon price before the game was run; instead, the assumed carbon prices skewed significantly higher than the expected carbon prices needed to meet the cap in the simulations (See Figure 11). As discussed in Section 2, one possible explanation is risk aversion, with players shading their assumed carbon prices higher to limit the risk of facing non-compliance penalties or the need to buy carbon allowances at a high price after the last electricity market period. Another possible explanation could be that the assumed carbon price is a coordinating mechanism for pushing electricity prices higher. Finally, it could be that inefficiencies in the merit order produced by the players' collective pricing actually required higher carbon prices to keep emissions under the cap. Later in this paper, we will consider the evidence for each of these hypotheses.

Higher electricity prices translated into more variable and, on average, substantially higher profits for generators in the cap-and-trade games, as shown in Tables 12 and 13 as well as the histograms of Figure 12. Table 14 confirms that the effect on genco profits was statistically significant as well as large ${ }^{20}$. At the same time, as shown in Table 15, total $\mathrm{CO}_{2}$ emissions did not show a clear systematic change in moving from cap and trade to a carbon tax across matched emissions target (TI: Cap I/Tax I; TII: Cap II/Tax II), matched mean emissions target (ME: Cap III/Tax III), and matched carbon price (MCP: Cap I/Tax II) treatment pairs. $^{21}$

Emissions were comparable between carbon pricing policies despite the fact that electricity generation was higher in the carbon tax case (Table 16), a function of the lower

\footnotetext{
${ }^{20}$ Note generating companies were charged by the government for their initial allowances (see Table 3 for the price they were charged)

${ }^{21}$ There was also no discernible difference in the number of wind generation units built under any of the treatments.
} 
electricity prices. The reason emissions remained comparable was that there was significantly more generation from the "dirtiest" generation units - coal units and low-efficiency gas peaker units - in the cap-and-trade games (see Table 17). An important part of the explanation, which will be explored further in Section 4.2, is that players did not always agree in the carbon prices they assumed under cap-and-trade (see Table 18). This allowed high-carbon generation units whose owners assumed a low carbon price to run ahead of lower-carbon generation units whose owners assumed a higher carbon price.

Because emissions under the cap-and-trade system were broadly the same as under the carbon tax, while electricity prices were substantially higher, the consumer surplus was markedly lower in the cap-and-trade case (Table 19). In effect, consumers paid much more for emissions reductions under the cap-and-trade system.

In the remainder of this paper, we explore the factors that may have led to the above observations, and what they imply about the relative strengths and weaknesses of carbontax and cap-and-trade policies under uncertainty. First, we consider how uncertainty in the carbon price due to imperfect foreknowledge might lead to inefficiencies in cap-and-trade systems. Second, we consider the evidence that risk aversion with regard to compliance penalties may have led to inflated carbon prices in the cap-and-trade game. Third, we assess whether carbon price could act as a mechanism to facilitate the exercise of market power in the electricity market. ${ }^{22}$

\footnotetext{
${ }^{22}$ As an example of such behavior in another emissions market, Kolstad and Wolak (2013) found that high $\mathrm{NO}_{x}$ permit prices in the SCAQMD market (in Southern California) during the Western U.S. Energy crisis of 2000 and 2001 were used as a means for generators to justify higher electricity market offers that would increase prices.
} 


\subsection{Effects of carbon price uncertainty}

Table 10 and Table 18 show that both unconditional and conditional variance, respectively, of carbon prices assumed by players in their price offers was significantly higher in the capand-trade game than in the carbon tax game. This was expected, as the carbon price was known in the carbon tax game - it was the tax - while it was market-determined in the capand-trade game. Players rationally adjusted their carbon price expectations over the course of each cap-and-trade game depending on whether total emissions appeared to be trending over or under the cap. ${ }^{23}$ This would naturally cause some variation in carbon price across the game periods.

However, there was an additional source of variation in the assumed carbon price, and that was the variation between the eight players in a game in the carbon prices they assumed within a period. Figure 13 shows that this variation was quite significant in the cap-andtrade games. As discussed in section 4.1, disagreement in assumed carbon price among players was likely a major reason why more "dirty" generation units (coal generation units and low efficiency gas peaker generation units) ran in the cap-and-trade games, as indicated by Table 17. When all market participants agree on the carbon price, it produces the "proper" shifts in merit order, causing fewer high-emitting generation units to run as carbon price increases because their operating costs go up accordingly. When, on the other hand, there is disagreement on the carbon price market participants factor into their offers, dirtier generation units may end up running simply because their owner assumed a lower carbon price than other market participants.

The effect of this variation in carbon price forecasts is to make emissions mitigation and

\footnotetext{
${ }^{23}$ If, for example, total emissions were at $65 \%$ of the cap after $3(75 \%)$ of the 4 electricity market periods had been run, players could see that it was unlikely emissions would exceed the cap, and adjust their carbon price expectations downward accordingly.
} 
electricity market functioning less efficient under the cap-and-trade program. "Errors" in the merit order that are caused by carbon price disagreement have the effect of increasing total generation costs. To illustrate this phenomenon, Figure 14 simulates how a given level of carbon price disagreement would affect total generation costs for the game configurations we ran. Assumed carbon price for each of the eight players is modeled as a normally-distributed random variable, with the standard deviation increased from 0 (second chart from top) to 50 (bottom chart). ${ }^{24}$ As standard deviation of assumed carbon price is increased in the simulation of Figure 14, average generation costs increase, and their variance grows larger.

One source of variation in carbon price expectations can be limited or asymmetric information. All players in our games had access to significant information about the carbon market. They could see all the bid and ask offers submitted to the market during allowance trading, and they were given the volume-weighted carbon price for all the transactions executed in a trading period once that trading period had closed. Nevertheless, Figure 13 suggests this information was not sufficient to keep carbon price expectations among players within in a tight range. Perhaps the remaining price disagreements were the product of illiquid carbon markets that did not send clear enough price signals. Perhaps players varied in their willingness to accept the risk of being short on permits at the end. Or perhaps there were irreconcilable differences between players in where they believed carbon prices would end up. Some of these issues could have been accentuated by the relatively short duration of the games and the relatively small size of the markets (eight market participants). However, as we discuss in Section 5, there is reason to believe the same phenomena factor into real-world markets as well.

\footnotetext{
${ }^{24}$ As shown in Figure 13, the standard deviation of assumed carbon prices in our actual games was frequently higher than 50 .
} 


\subsection{Possible reasons for high carbon prices in cap-and-trade games}

Why are carbon prices so much higher on average in the cap-and-trade games? We consider the evidence for three possible explanations: 1) that this represents risk-averse offer behavior from players that fear being left short of allowances at the end of the game, 2) that carbon price acts as an implicit coordination mechanism for the exercise of market power in the electricity market, and 3) that merit order inefficiencies due to the disagreement on carbon price discussed above allow high carbon prices to persist even in the absence of the other two mechanisms.

Dormady (2014) raises the possibility that emitters might pay high prices for allowances early in a compliance period out of fear of being left short at the end. These high carbon prices would tend to reduce emissions in the wholesale electricity market, and carbon prices would subsequently decline as market participants realized emissions would be comfortably under the cap. This is the "declining price anomaly" identified by (McAfee and Vincent, 1993) as a possibility in emissions markets.

Figure 15, which shows the mean assumed carbon price by period for each game, suggests that the declining price anomaly is not being observed here, at least not to a significant extent. If anything, assumed carbon prices tended to rise over the four trading periods rather than fall. Traded carbon prices corroborate this finding of no declining price anomaly (see Figure 16). In some games (for example the Cap I games in round 4) allowance prices

drop over time as it becomes apparent there is an oversupply of allowances, and in other games (for example the Cap II games in round 1) prices rise as it becomes apparent that emissions are high relative to the cap. However, there is no systematic trend of decreasing price.

These high carbon prices might indicate some degree of defensive pricing, as emitters 
hedge against the possibility of low wind output in late periods, which could cause emissions to go higher relative to the cap. The substantial non-compliance penalties in the game might predispose players to defensive behavior. However, it is notable that assumed carbon prices do not on average drop over time, as one might have expected if high initial assumed carbon prices pushed emissions down.

The fact that emissions were not systematically lower in the cap-and-trade games suggests that the high mean values for assumed carbon price in Figure 15 were for the most part needed to hold emissions under the cap given the disagreement in assumed carbon price between players (Figure 14). If some players ended up running their high-emitting generation units at high rates because they factored lower carbon prices into offers, other players would be rational to assume higher carbon prices, which would restrain emissions from their own portfolios (and limit their need to buy - or use up-high-value carbon allowances). This seeming equilibrium, in which gencos factored in carbon prices that were high on average but widely varying, benefited all gencos by significantly increasing average electricity prices. As discussed in Section 4.1, it also hurt consumer welfare.

For the most part, there was limited evidence that players explicitly used carbon price as a coordinating mechanism for exercising market power to increase electricity prices. It appears that the equilibrium of high and variable assumed carbon prices was more of a "happy accident" for genco profitability rather than a deliberate strategy to increase electricity market profits. That said, there appeared to be some players who used the "assumed carbon price" feature in the price offer screen as a shorthand means of raising their wholesale electricity market offers. Notably, some players used this feature to factor in a high carbon price even in the carbon tax games, for which carbon price was known to be between $\$ 120$ and $\$ 136.21$. These higher assumed carbon prices in the carbon tax games are visible as 
high outliers in Figure 17, which plots every player's assumed carbon price in every period of every game. We have no way of knowing if these players also would have priced high if the option to automatically factor an assumed carbon price into offers had not been available.

\section{Conclusions}

By the logic of Weitzman (1974), price-based and quantity-based policy instruments can never be truly equivalent under uncertainty. In the absence of clear real-world or theoretical evidence on how the market resolves uncertainty for price-based versus quantity-based modes of carbon pricing, we turned to a game-based experiment. For purposes of comparison, we defined matched pairs of carbon-tax/cap-and-trade scenarios that were equivalent on three separate dimensions: emissions target, mean emissions, and mean carbon price. Across these matched pairs, the cap-and-trade mechanism produced much higher electricity spot market prices (38.5\% to $52.6 \%$ higher) and lower total electrical generation (2.5\% to $4.0 \%$ lower) than the "equivalent" carbon tax, without any significant decrease in carbon emissions. This occurred in part because emissions from the dirtiest generating units (Coal and Gas Peakers) were significantly higher $(15.2 \%$ to $33.0 \%)$ in the cap-and-trade games. These results suggest an important practical reason why cap-and-trade policies may struggle in practice to match the economic efficiency of a carbon tax. Namely, under the conditions of uncertainty faced by real-world market participants, variation in the carbon prices assumed by emitters can result in inefficient emissions reduction. The market participant who assumes the lowest carbon price will run their units the most, and the market participant who forecasts the highest carbon price will run their units the least, irrespective of unit characteristics. In the case of our cap-and-trade games, this disagreement in assumed carbon price permitted more high-emitting generation units to run and also meant a higher average carbon price 
was needed to keep emissions near the cap. Inefficient dispatch increased generation costs relative to comparable carbon tax games.

There is reason to believe that disagreement in carbon price forecasts between market participants could be an important feature of real-world carbon markets as well. These markets tend to be relatively illiquid, with price discovery that is not always easy. Moreover, carbon prices can be volatile, and they may swing between extreme values depending on available information about the balance between allowance supply and allowance demand. For example, the allowance spot price in the EU ETS dropped from about EUR 30 per tonne of $\mathrm{CO}_{2}$ to near zero in September 2007 after information emerged showing allowance supply was ample to cover emissions. The EU carbon price recovered but has continued to fluctuate significantly since then, in part in response to policy actions by governments. Given this level of real-world uncertainty, we believe disagreement in carbon price forecasts among electricity generators is likely to be a real phenomenon that merits further investigation due to its potentially deleterious effects on electricity market functioning. Policy measures that increase transparency around carbon allowance trades and electricity market offers might help build consensus among market participants about the "correct" carbon price at any point in time, although it seems unlikely to completely harmonize carbon price expectations. In electricity markets, the merit order of generation unit dispatch will remain inefficient as long as carbon pricing disagreements remain. ${ }^{25}$ The presence of credible floor and ceiling prices for carbon could mitigate this problem to some extent.

The results described in this paper point to a fundamental real-world difference between carbon-tax and cap-and-trade systems as instruments for pricing carbon. Namely, a carbon tax is treated by market participants as a known input to production, whereas a cap-and-

\footnotetext{
${ }^{25}$ And to the extent that such disagreement pushes up electricity prices, generators for their part have no incentive to rectify the situation.
} 
trade system does not afford the same clarity. With cap and trade, there will always be some range of expectations about the current carbon price among market participants, and the spread between the most optimistic and pessimistic estimates will necessarily introduce inefficiency and uncertainty. Our results reveal a significant market efficiency benefit from a carbon tax relative to a cap-and-trade mechanism in instances where there is emissions demand uncertainty and imperfect competition in the electricity market and market for emissions allowances. These results also support the existence of market efficiency benefits from maximizing transparency around allowance holdings as well as a floor and a ceiling price for carbon. Such measures may help mitigate the negative effects of disagreement on carbon price among market participants.

\section{References}

Aldy, J. E., J.Krupnick, A., Newell, R. G., Parry, I. W., and Pizer, W. A. (2010). Designing climate mitigation policy. Journal of Economic Literature.

Borenstein, S., Bushnell, J., Wolak, F. A., and Zaragoza-Watkins, M. (2014). Report of the market simulation group on competitive supply/demand balance in the california allowance market and the potential for market manipulation. Working paper 251, Energy Institute at Haas.

Borenstein, S., Bushnell, J., Wolak, F. A., and Zaragoza-Watkins, M. (2019). Expecting the unexpected: Emissions uncertainty and environmental market design. American Economic Review, 109(11):3953-77.

Camacho-Cuena, E., Requate, T., and Waichman, I. (2012). Investment incentives under emission trading: An experimental study. Environmental and Resource Economics. 
Cason, T. N. and Gangadharan, L. (2006). Emissions variability in tradable permit markets with imperfect enforcement and banking. Journal of Economic Behaviour $\& 3$ Organizaton.

Davis, T. L. (2019). Features of the Energy Market Game. https://energymarketgame. org/pdf/features-of-the-energy-market-game.pdf.

Dormady, N. C. (2014). Carbon auctions, energy markets \& market power: An experimental analysis. Energy Economics.

Godby, R. (2000). Market power and emissions trading: theory and laboratory results. Pacific Economic Review.

Goeree, J. K., Palmer, K., Holt, C. A., Shobe, W., and Burtraw, D. (2010). An experimental study of auctions versus grandfathering to assign pollution permits. Journal of the European Economic Association.

Goulder, L. H. and Schein, A. R. (2013). Carbon taxes versus cap and trade: A critical review. Climate Change Economics.

Grimm, V. and Ilieva, L. (2013). An experiment on emissions trading: the effect of different allocation mechanisms. Journal of Regulatory Economics.

IPCC (2014). Climate change 2014: Mitigation of climate change. contribution of working group iii to the fifth assessment report of the intergovernmental panel on climate change. Technical report, IPCC.

Keohane, N. O. (2009). Cap and trade, rehabilitated: Using tradable permits to control U.S. greenhouse gases. Review of Environmental Economics and Policy. 
Kolstad, J. T. and Wolak, F. A. (2013). Using environmental emissions permit prices to raise electricity prices: Evidence from the California electricity market. Working paper.

Luong, D., Lee, T., Nguyen, D., Tsai, S., Chen, F., and Chau, E. (2003). Annual reclaim audit report for 2001 compliance year. Audit report, South Coast Air Quality Management District.

McAfee, R. P. and Vincent, D. (1993). The declining price anomaly. Journal of Economic Theory, 60(1):191-212.

Metcalf, G. E. (2009). Market-based policy options to control U.S. greenhouse gas emissions. Journal of Economic Perspectives.

Newell, R. G. and Pizer, W. A. (2003). Regulating stock externalities under uncertainty. Journal of Evironmental Economics and Management.

Stavins, R. N. (2007). A U.S. cap-and-trade system to address global climate change. The Hamilton Project: Discussion Paper 2007-13, The Brookings Institution.

Strand, J. (2013). Strategic climate policy with offsets and incomplete abatement: Carbon taxes versus cap-and-trade. Journal of Environmental Economics and Management.

Stranlund, J. K., Murphy, J. J., and Spraggon, J. M. (2011). An experimental analysis of compliance in dynamic emissions markets. Journal of Environmental Economics and Management.

Thurber, M. C., Davis, T. L., and Wolak, F. A. (2015). Simulating the interaction of a renewable portfolio standard with electricity and carbon markets. The Electricity Journal. 
Thurber, M. C. and Wolak, F. A. (2013). Carbon in the classroom: Lessons from a simulation of california's electricity market under a stringent cap and trade system. The Electricity Journal, 26:8-21.

van Koten, S. (2015). Do emission trading schemes facilitate efficient abatement investments? an experimental study. Working paper, EUI.

Wara, M. W. and Victor, D. G. (2008). A realistic policy on international carbon offsets. Working paper 74, Stanford University Program on Energy and Sustainable Development.

Weitzman, M. L. (1974). Prices vs. quantities. Review of Economic Studies, pages 477-491.

Wråke, M., Myers, E., Burtraw, D., Mandell, S., and Holt, C. (2010). Opportunity cost for free allocations of emissions permits: An experimental analysis. Environmental and Resource Economics. 


\section{Tables and Figures}

Table 1: Previous experimental research on carbon pricing

\begin{tabular}{|l|l|l|l|}
\hline Paper & Abatement mechanisms & Permits & Electricity \\
\hline \hline Dormady (2014) & None & 10 & 10 \\
Godby (2000) & Fixed abatement costs & 6,11 & 6,11 \\
Goeree et al. (2010) & Merit-order shift, Demand reduction & 6 & 6 \\
Cason and Gangadharan (2006) & Partially selectable abatement costs & 8 & 8 \\
Stranlund et al. (2011) & Supply reduction & 8 & $\infty$ \\
Grimm and Ilieva (2013) & Increasing abatement costs & 16 & $\infty$ \\
Camacho-Cuena et al. (2012) & Investible abatement costs & 18 & $\infty$ \\
van Koten (2015) & Investible abatement costs & $\infty$ & $\infty$ \\
Wråke et al. (2010) & None & $\infty$ & $\infty$ \\
\hline This paper & Merit-order shift, Demand reduction, New generation units & $8, \infty$ & 8 \\
\hline \hline
\end{tabular}

Note: The (Emissions) Permits and Electricity columns show how many subjects participated in the relevant market with a comma meaning there were treatments with differing number of subjects. $\infty$ meant that the subjects were price-takers, in the case of the Permits column this means that even if the game was presented in its paper as a cap-and-trade game it was effectively an emissions-tax game. In the Abatement mechanisms column "None" meant there was no mechanism to reduce overall emissions, "Fixed abatement costs" meant that un-permitted emissions were fully abated at a fixed cost, "Increasing abatement costs" meant that un-permitted emissions were fully abated at an increasing cost, "Investible abatement costs" meant that players could pay money to invest in new technologies to reduce the cost to abate the $\mathrm{CO}_{2}$ emissions for a generation unit, "Merit-order shift" means that a carbon-price could lead to an emissions reduction by inducing a merit-order shift, "Demand reduction" means that a carbon-price could lead to an emissions reduction by reducing demand, and "New generation units" means that a carbon-price could lead to an emissions reduction by adding new more efficient generation units to the existing stock of generation units. 
Table 2: Portfolios

\begin{tabular}{|c|c|c|c|c|c|c|}
\hline Name & Type & Notes & Mean capacity & Variable cost & Fixed cost & Emissions Rate \\
\hline \hline Wind & Old Wind 1 & Retires after period 1 & 240 & $\$ 0$ & $\$ 0$ & 0 \\
\hline Wind & Old Wind 2 & Retires after period 2 & 240 & $\$ 0$ & $\$ 0$ & 0 \\
\hline Wind & New Wind & $\begin{array}{c}\text { buy up to two per period } \\
\text { period delay until online }\end{array}$ & 240 & $\$ 0$ & $\$ 33,600$ & 0 \\
\hline \hline Coal & Coal 1 & & 300 & $\$ 17$ & $\$ 0$ & 1.00 \\
\hline Coal & Coal 2 & 300 & $\$ 20$ & $\$ 0$ & 1.10 \\
\hline Gas & Gas Base & 800 & $\$ 30$ & $\$ 0$ & 0.55 \\
\hline Gas & Gas Mid 1 & & 400 & $\$ 40$ & $\$ 0$ & 0.70 \\
\hline Gas & Gas Mid 2 & & $\$ 00$ & $\$ 45$ & $\$ 0$ & 0.80 \\
\hline Gas & Gas Peak & & 800 & $\$ 60$ & $\$ 0$ & 1.10 \\
\hline \hline & & Total Starting & 3,480 & & & \\
\hline
\end{tabular}

Table 3: Game treatment conditions

\begin{tabular}{|l|l|l|l|l|}
\hline Treatment & Tax & Cap & Initial Allowance Cost & Year \\
\hline \hline Cap I & & 32,704 tonnes & $\$ 136.21$ & 2017 \\
\hline Tax I & $\$ 127$ & & & 2017 \\
\hline Cap II & & 32,560 tonnes & $\$ 140.83$ & 2017 \\
\hline Tax II & $\$ 136.21$ & & & 2017 \\
\hline Cap III & & 33,152 tonnes & $\$ 120$ & 2016 \\
\hline Tax III & $\$ 120$ & & & 2016 \\
\hline
\end{tabular}

Table 4: Simulation statistics

\begin{tabular}{|l|l|l|l|}
\hline Treatment & Carbon Price Mean (SD) & Emissions Mean (SD) & Cap used in Calculation \\
\hline \hline Cap I & $\$ 136.21(88.90)$ & $32,464(337)$ & $32,697.43$ \\
\hline Tax I & $\$ 127.00(0.00)$ & $32,697(2,687)$ & \\
\hline Cap II & $\$ 140.83(91.55)$ & $32,328(329)$ & $32,552.11$ \\
\hline Tax II & $\$ 136.21(0.00)$ & $32,552(2,693)$ & \\
\hline Cap III & $\$ 123.68(81.44)$ & $32,887(355)$ & $33,145.30$ \\
\hline Tax III & $\$ 120.00(0.00)$ & $32,808(2,683)$ & \\
\hline
\end{tabular}

Table 5: "Equivalent" comparisons assuming marginal cost pricing and 16 wind units

\begin{tabular}{|l|l|l|l|}
\hline Label & Equivalency & Treatments & \multicolumn{1}{|c|}{ Differences } \\
\hline \hline TI & SP Emissions Target (I) & Cap I and Tax I & Target Emissions differ by $0.02 \%$ \\
\hline TII & SP Emissions Target (II) & Cap II and Tax II & Target Emissions differ by $0.02 \%$ \\
\hline ME & SP Emissions Mean & Cap III and Tax III & Mean Emissions differ by $0.24 \%$ \\
\hline MCP & SP Carbon Price Mean & Cap I and Tax II & \\
\hline
\end{tabular}


Table 6: Round $\times$ Game $\times$ Period data

carbon-tax I treatment summary statistics:

\begin{tabular}{lccccc}
\hline \hline Statistic & $\mathrm{N}$ & Mean & St. Dev. & Min & Max \\
\hline market_price & 80 & 144.612 & 8.502 & 102.850 & 159.700 \\
\hline \multicolumn{5}{c}{ carbon-tax } & II treatment summary \\
\hline \hline Statistic & $\mathrm{N}$ & Mean & St. Dev. & Min & Max \\
\hline market_price & 80 & 152.109 & 9.036 & 107.920 & 169.830 \\
\hline
\end{tabular}

carbon-tax III treatment summary statistics:

\begin{tabular}{lccccc}
\hline \hline Statistic & N & Mean & St. Dev. & Min & Max \\
\hline market_price & 160 & 145.100 & 9.808 & 124.000 & 192.000 \\
\hline
\end{tabular}

cap-and-trade I treatment summary statistics:

\begin{tabular}{lccccc}
\hline \hline Statistic & N & Mean & St. Dev. & Min & Max \\
\hline market_price & 80 & 231.003 & 65.123 & 133.000 & 450.000 \\
\hline
\end{tabular}

cap-and-trade II treatment summary statistics:

\begin{tabular}{lccccc}
\hline \hline Statistic & N & Mean & St. Dev. & Min & Max \\
\hline market_price & 80 & 246.863 & 64.626 & 160.000 & 500.000 \\
\hline
\end{tabular}

cap-and-trade III treatment summary statistics:

\begin{tabular}{lccccc}
\hline \hline Statistic & $\mathrm{N}$ & Mean & St. Dev. & Min & Max \\
\hline market_price & 160 & 234.220 & 81.316 & 99.000 & 500.000 \\
\hline
\end{tabular}


Table 7: Estimated mean effect on logged wholesale electricity prices (\$/MWh)

\begin{tabular}{lcccc}
\hline \hline & & & & \\
& TI & TII & ME & MCP \\
& $(1)$ & $(2)$ & $(3)$ & $(4)$ \\
\hline treatment carbon_tax FE & $-0.435^{* * *}$ & $-0.457^{* * *}$ & $-0.427^{* * *}$ & $-0.385^{* * *}$ \\
& $(0.027)$ & $(0.024)$ & $(0.023)$ & $(0.026)$ \\
\hline Seed FE & & & & \\
Period FE & $\mathrm{X}$ & $\mathrm{X}$ & $\mathrm{X}$ & $\mathrm{X}$ \\
\hline \hline Note: & $\mathrm{X}$ & $\mathrm{X}$ & $\mathrm{X}$ & $\mathrm{X}$ \\
\hline
\end{tabular}

Robust standard errors. Note seed fixed effects also serve as year x round fixed effects. Columns represent which "equivalent" cap-and-trade and carbon tax treatments the effect was estimated on. See Table 5 for the exact comparisons. 
Table 8: Round $\times$ Game $\times$ Period $\times$ Player $\times$ Generation Unit data carbon-tax treatment I summary statistics:

\begin{tabular}{lccccccc}
\hline \hline Statistic & $\mathrm{N}$ & Mean & St. Dev. & Min & Pctl(25) & Pctl(75) & Max \\
\hline offer.price & 3,840 & 155.738 & 57.486 & 0 & 128.9 & 159.7 & 500 \\
\hline \multicolumn{7}{c}{ carbon-tax treatment II } & summary statistics: \\
\hline \hline Statistic & $\mathrm{N}$ & Mean & St. Dev. & Min & Pctl(25) & Pctl(75) & Max \\
\hline offer.price & 3,840 & 161.563 & 54.893 & 0 & 135.3 & 169.8 & 500 \\
\hline \multicolumn{7}{c}{ carbon-tax treatment III } & summary statistics: \\
\hline \hline
\end{tabular}

\begin{tabular}{lccccccc}
\hline \hline Statistic & N & Mean & St. Dev. & Min & Pctl(25) & Pctl(75) & Max \\
\hline offer.price & 7,680 & 180.549 & 114.325 & 0 & 124 & 180 & 500 \\
\hline
\end{tabular}

cap-and-trade treatment I summary statistics:

\begin{tabular}{lccccccc}
\hline \hline Statistic & N & Mean & St. Dev. & Min & Pctl(25) & Pctl(75) & Max \\
\hline offer.price & 3,840 & 269.055 & 134.351 & 0 & 161 & 365 & 500 \\
\hline
\end{tabular}

cap-and-trade treatment II summary statistics:

\begin{tabular}{lccccccc}
\hline \hline Statistic & $\mathrm{N}$ & Mean & St. Dev. & Min & Pctl(25) & Pctl(75) & Max \\
\hline offer.price & 3,840 & 283.840 & 138.031 & 0 & 172.1 & 400 & 500 \\
\hline
\end{tabular}

cap-and-trade treatment III summary statistics:

\begin{tabular}{lccccccc}
\hline \hline Statistic & N & Mean & St. Dev. & Min & Pctl(25) & Pctl(75) & Max \\
\hline offer.price & 7,680 & 273.267 & 147.672 & 0 & 145 & 417 & 500 \\
\hline
\end{tabular}


Table 9: Estimated mean effect on generation unit price offers $(\$)$

\begin{tabular}{l} 
TI \\
\hline
\end{tabular}


Table 10: Round $\times$ Game $\times$ Period $\times$ Player carbon-tax I treatment summary statistics:

\begin{tabular}{lccccccc}
\hline \hline Statistic & $\mathrm{N}$ & Mean & St. Dev. & Min & Pctl(25) & Pctl(75) & Max \\
\hline assumed.carbon.price & 640 & 128.245 & 12.062 & 0 & 127 & 127 & 200 \\
\hline \multicolumn{7}{c}{ carbon-tax II treatment summary statistics: } \\
\hline \hline Statistic & $\mathrm{N}$ & Mean & St. Dev. & Min & Pctl(25) & Pctl(75) & Max \\
\hline assumed.carbon.price & 640 & 137.100 & 5.398 & 100 & 136.2 & 136.2 & 200 \\
\hline \multicolumn{7}{c}{ carbon-tax III treatment summary } & statistics: \\
\hline \hline Statistic & $\mathrm{N}$ & Mean & St. Dev. & Min & Pctl(25) & Pctl(75) & Max \\
\hline assumed.carbon.price & 320 & 123.824 & 22.136 & 0.000 & 120.000 & 120.000 & 400.000 \\
\hline cap-and-trade I treatment summary statistics: \\
\hline \hline Statistic & $\mathrm{N}$ & Mean & St. Dev. & Min & Pctl(25) & Pctl(75) & Max \\
\hline assumed.carbon.price & 640 & 207.705 & 86.829 & 10.000 & 136.210 & 250.000 & 400.000 \\
\hline
\end{tabular}

cap-and-trade II treatment summary statistics:

\begin{tabular}{lccccccc}
\hline \hline Statistic & N & Mean & St. Dev. & Min & Pctl(25) & Pctl(75) & Max \\
\hline assumed.carbon.price & 640 & 215.156 & 84.733 & 0.000 & 140.830 & 270.000 & 400.000 \\
\hline
\end{tabular}

cap-and-trade III treatment summary statistics:

\begin{tabular}{lccccccc}
\hline \hline Statistic & N & Mean & St. Dev. & Min & Pctl(25) & Pctl(75) & Max \\
\hline assumed.carbon.price & 320 & 201.101 & 110.866 & 0.000 & 120.000 & 282.500 & 400.000 \\
\hline
\end{tabular}


Table 11: Estimated mean effect on assumed carbon prices $(\$)$

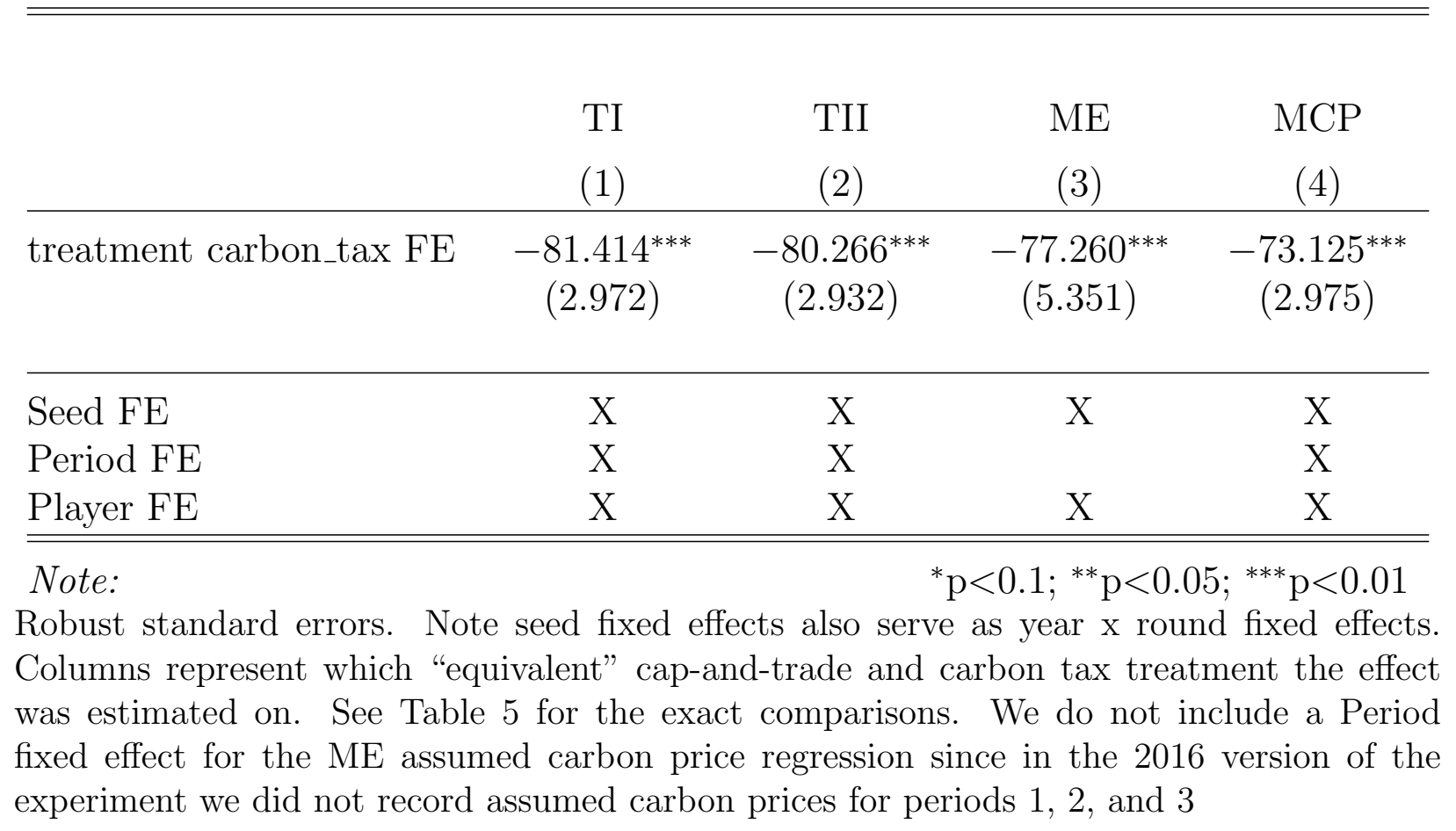


Table 12: Round $\times$ Game (carbon-tax treatments)

carbon-tax I treatment summary statistics:

\begin{tabular}{lccccccc}
\hline \hline Statistic & $\mathrm{N}$ & Mean & St. Dev. & Min & Pctl(25) & Pctl(75) \\
\hline co2_emissions & 20 & $31,542.700$ & $2,883.894$ & 26,443 & $29,633.5$ & $33,283.8$ \\
genco_profits & 20 & $2,019,771.000$ & $380,279.300$ & $1,387,086.000$ & $1,678,818.000$ & $2,327,232.000$ & $2,575,301.000$ \\
electricity_generated & 20 & $63,927.300$ & 81.177 & 63,757 & $63,891.8$ & $63,960.8$ & 64,136 \\
dirty_electricity_generated & 20 & $6,797.700$ & $1,467.926$ & 4,240 & $5,604.2$ & $7,740.8$ & 9,495 \\
consumer_surplus & 20 & $102,168,941.000$ & $258,242.600$ & $101,624,299.000$ & $102,053,203.000$ & $102,270,385.000$ & $102,833,738.000$ \\
government_revenue & 20 & $4,005,923.000$ & $366,254.500$ & $3,358,261$ & $3,763,454.0$ & $4,227,036.0$ & $4,614,799$ \\
carbon_social_cost_0 & 20 & 0.000 & 0.000 & 0 & 0 & 0 \\
carbon_social_cost_120 & 20 & $3,785,124.000$ & $346,067.200$ & $3,173,160$ & $3,556,020$ & $3,994,050$ \\
carbon_social_cost_140 & 20 & $4,415,978.000$ & $403,745.100$ & $3,702,020$ & $4,148,690$ & $4,659,725$ \\
cs_gp_and_gr_minus_sc_0 & 20 & $108,194,634.000$ & $240,719.000$ & $107,824,456.000$ & $108,045,228.000$ & $108,343,298.000$ & $108,565,665.000$ \\
cs_gp_and_gr_minus_sc_120 & 20 & $104,409,510.000$ & $422,072.000$ & $103,729,583.000$ & $104,213,763.000$ & $104,645,734.000$ & $105,153,692.000$ \\
cs_gp_and_gr_minus_sc_140 & 20 & $103,778,656.000$ & $470,600.800$ & $103,044,243.000$ & $103,545,808.000$ & $104,021,915.000$ & $104,624,832.000$ \\
\hline
\end{tabular}

carbon-tax II treatment summary statistics:

\begin{tabular}{|c|c|c|c|c|c|c|c|}
\hline Statistic & $\mathrm{N}$ & Mean & St. Dev. & Min & $\operatorname{Pctl}(25)$ & $\operatorname{Pctl}(75)$ & $\operatorname{Max}$ \\
\hline co2_emissions & 20 & $31,094.000$ & $2,930.346$ & 25,768 & $29,561.8$ & $33,560.5$ & 35,092 \\
\hline genco_profits & 20 & $2,248,929.000$ & $346,656.600$ & $1,616,717.000$ & $2,031,043.000$ & $2,513,286.000$ & $2,828,000.000$ \\
\hline electricity_generated & 20 & $63,777.100$ & 103.692 & 63,555 & 63,744 & 63,838 & 64,069 \\
\hline dirty_electricity_generated & 20 & $6,217.100$ & $1,504.946$ & 3,000 & $5,475.2$ & 7,313 & 9,276 \\
\hline consumer_surplus & 20 & $101,689,925.000$ & $331,162.300$ & $100,981,547.000$ & $101,586,185.000$ & $101,883,608.000$ & $102,622,617.000$ \\
\hline government_revenue & 20 & $4,235,314.000$ & $399,142.400$ & $3,509,859.000$ & $4,026,606.000$ & $4,571,276.000$ & $4,779,881.000$ \\
\hline carbon_social_cost_0 & 20 & 0.000 & 0.000 & 0 & 0 & 0 & 0 \\
\hline carbon_social_cost_120 & 20 & $3,731,280.000$ & $351,641.500$ & $3,092,160$ & $3,547,410$ & $4,027,260$ & $4,211,040$ \\
\hline carbon_social_cost_140 & 20 & $4,353,160.000$ & $410,248.400$ & $3,607,520$ & $4,138,645$ & $4,698,470$ & $4,912,880$ \\
\hline cs_gp_and_gr_minus_sc_0 & 20 & $108,174,168.000$ & $203,799.900$ & $107,765,143.000$ & $108,057,529.000$ & $108,363,613.000$ & $108,421,514.000$ \\
\hline cs_gp_and_gr_minus_sc_120 & 20 & $104,442,888.000$ & $447,689.000$ & $103,743,103.000$ & $104,224,627.000$ & $104,676,622.000$ & $105,133,383.000$ \\
\hline cs_gp_and_gr_minus_sc_140 & 20 & $103,821,008.000$ & $500,949.800$ & $103,072,763.000$ & $103,613,114.000$ & $104,072,742.000$ & $104,614,738.000$ \\
\hline
\end{tabular}

carbon-tax III treatment summary statistics:

\begin{tabular}{|c|c|c|c|c|c|c|c|}
\hline Statistic & $\mathrm{N}$ & Mean & St. Dev. & Min & $\operatorname{Pctl}(25)$ & $\operatorname{Pctl}(75)$ & Max \\
\hline co2_emissions & 40 & $34,685.220$ & $2,938.527$ & 27,076 & $33,362.2$ & $36,495.2$ & 39,990 \\
\hline genco_profits & 40 & $2,089,032.000$ & $428,330.800$ & $984,495.000$ & $1,830,074.000$ & $2,433,924.000$ & $3,273,901.000$ \\
\hline electricity_generated & 40 & $63,918.000$ & 135.913 & 63,542 & $63,887.5$ & $64,002.5$ & 64,090 \\
\hline dirty_electricity_generated & 40 & $8,596.519$ & $1,688.215$ & $3,540.818$ & $7,652.663$ & $9,704.714$ & $11,751.930$ \\
\hline consumer_surplus & 40 & $102,138,716.000$ & $433,240.400$ & $100,944,083.000$ & $102,040,665.000$ & $102,408,061.000$ & $102,688,210.000$ \\
\hline government_revenue & 40 & $4,162,227.000$ & $352,623.200$ & $3,249,120$ & $4,003,470$ & $4,379,430$ & $4,798,800$ \\
\hline carbon_social_cost_0 & 40 & 0.000 & 0.000 & 0 & 0 & 0 & 0 \\
\hline carbon_social_cost_120 & 40 & $4,162,227.000$ & $352,623.200$ & $3,249,120$ & $4,003,470$ & $4,379,430$ & $4,798,800$ \\
\hline carbon_social_cost_140 & 40 & $4,855,932.000$ & $411,393.800$ & $3,790,640$ & $4,670,715$ & $5,109,335$ & $5,598,600$ \\
\hline cs_gp_and_gr_minus_sc_0 & 40 & $108,389,975.000$ & $248,867.100$ & $107,866,615.000$ & $108,240,371.000$ & $108,561,406.000$ & $109,060,286.000$ \\
\hline cs_gp_and_gr_minus_sc_120 & 40 & $104,227,748.000$ & $409,297.000$ & $103,384,495.000$ & $103,925,300.000$ & $104,525,681.000$ & $105,054,316.000$ \\
\hline cs_gp_and_gr_minus_sc_140 & 40 & $103,534,043.000$ & $457,493.200$ & $102,637,475.000$ & $103,177,333.000$ & $103,857,735.000$ & $104,512,796.000$ \\
\hline
\end{tabular}




\section{Table 13: Round $\times$ Game (cap-and-trade treatments)}

cap-and-trade I treatment summary statistics:

\begin{tabular}{|c|c|c|c|c|c|c|c|}
\hline Statistic & $\mathrm{N}$ & Mean & St. Dev. & Min & $\operatorname{Pctl}(25)$ & $\operatorname{Pctl}(75)$ & Max \\
\hline co2_emissions & 20 & $32,058.150$ & $3,636.451$ & 26,731 & $29,963.2$ & 34,433 & 38,855 \\
\hline genco_profits & 20 & $6,016,940.000$ & $2,587,682.000$ & $2,728,584.000$ & $4,673,560.000$ & $6,783,110.000$ & $13,331,018.000$ \\
\hline electricity_generated & 20 & $62,199.850$ & 943.314 & 59,651 & $61,789.8$ & 62,708 & 63,570 \\
\hline dirty_electricity_generated & 20 & $8,547.600$ & $3,111.508$ & 4,887 & 6,321 & $9,508.8$ & 15,325 \\
\hline consumer_surplus & 20 & $96,762,555.000$ & $2,894,131.000$ & $89,017,730.000$ & $95,466,550.000$ & $98,339,436.000$ & $101,032,153.000$ \\
\hline government_revenue & 20 & $5,055,272.000$ & $836,424.400$ & $4,454,612.000$ & $4,454,612.000$ & $5,287,512.000$ & $7,403,012.000$ \\
\hline carbon_social_cost_0 & 20 & 0.000 & 0.000 & 0 & 0 & 0 & 0 \\
\hline ial_cost_120 & 20 & $3,846,978.000$ & $436,374.100$ & $3,207,720$ & $3,595,590$ & $4,131,960$ & $4,662,600$ \\
\hline carbon_social_cost_140 & 20 & $4,488,141.000$ & $509,103.100$ & $3,742,340$ & $4,194,855$ & $4,820,620$ & $5,439,700$ \\
\hline cs_gp_and_gr_minus_sc_0 & 20 & $107,834,766.000$ & $310,728.800$ & $107,238,564.000$ & $107,640,405.000$ & $108,051,501.000$ & $108,215,349.000$ \\
\hline cs_gp_and_gr_minus_sc_120 & 20 & $103,987,788.000$ & $553,372.000$ & $103,140,301.000$ & $103,500,972.000$ & $104,290,203.000$ & $105,007,629.000$ \\
\hline cs_gp_and_gr_minus_sc_140 & 20 & $103,346,625.000$ & $614,973.000$ & $102,363,201.000$ & $102,808,715.000$ & $103,653,808.000$ & $104,473,009.000$ \\
\hline
\end{tabular}

cap-and-trade II treatment summary statistics:

\begin{tabular}{|c|c|c|c|c|c|c|c|}
\hline Statistic & $\mathrm{N}$ & Mean & St. Dev. & Min & $\operatorname{Pctl}(25)$ & $\operatorname{Pctl}(75)$ & Max \\
\hline co2_emissions & 20 & $31,542.400$ & $3,473.541$ & 25,433 & 28,166 & 34,215 & 36,749 \\
\hline genco_profits & 20 & $6,928,051.000$ & $2,467,789.000$ & $2,322,962.000$ & $5,499,698.000$ & $8,520,528.000$ & $12,662,336.000$ \\
\hline lectricity_generated & 20 & $61,882.700$ & 748.216 & 59,796 & $61,494.8$ & $62,442.2$ & 62,944 \\
\hline dirty_electricity_generated & 20 & $8,027.350$ & $2,234.416$ & 3,827 & 6,284 & $9,339.2$ & 12,291 \\
\hline consumer_surplus & 20 & $95,777,990.000$ & $2,276,538.000$ & $89,529,109.000$ & $94,561,108.000$ & $97,486,297.000$ & $99,049,210.000$ \\
\hline government_revenue & 20 & $5,062,485.000$ & $722,347.300$ & $4,585,425.000$ & $4,585,425.000$ & $5,247,425.000$ & $6,965,025.000$ \\
\hline carbon_social_cost_0 & 20 & 0.000 & 0.000 & 0 & 0 & 0 & 0 \\
\hline carbon_social_cost_120 & 20 & $3,785,088.000$ & $416,825.000$ & $3,051,9$ & $3,379,920$ & $4,105,800$ & $4,409,880$ \\
\hline carbon_social_cost_140 & 20 & $4,415,936.000$ & $486,295.800$ & $3,560,620$ & $3,943,240$ & $4,790,100$ & $5,144,860$ \\
\hline cs_gp_and_gr_minus_sc_0 & 20 & $107,768,525.000$ & $282,093.400$ & $106,970,869.000$ & $107,686,452.000$ & $107,889,382.000$ & $108,260,241.000$ \\
\hline cs_gp_and_gr_minus_sc_120 & 20 & $103,983,437.000$ & $492,620.000$ & $103,039,789.000$ & $103,624,288.000$ & $104,293,531.000$ & $104,750,136.000$ \\
\hline cs_gp_and_gr_minus_sc_140 & 20 & $103,352,589.000$ & $551,036.100$ & $102,384,609.000$ & $102,932,094.000$ & $103,737,666.000$ & $104,241,476.000$ \\
\hline
\end{tabular}

cap-and-trade III treatment summary statistics:

\begin{tabular}{lccccccc}
\hline \hline Statistic & N & Mean & St. Dev. & Min & Pctl(25) & Pctl(75) & Max \\
\hline co2_emissions & 40 & $33,387.100$ & $3,446.938$ & 24,368 & $30,853.5$ & $36,329.8$ & 39,042 \\
genco_profits & 40 & $6,366,335.000$ & $3,329,197.000$ & $1,181,605$ & $3,574,995.0$ & $8,541,004.0$ & $12,833,841$ \\
electricity_generated & 40 & $62,225.300$ & $1,358.741$ & 59,790 & $61,423.2$ & $63,338.5$ & 65,767 \\
dirty_electricity_generated & 40 & $10,173.920$ & $2,755.656$ & 5,649 & $7,897.5$ & $12,848.4$ & 14,576 \\
consumer_surplus & 40 & $96,731,941.000$ & $3,908,419.000$ & $89,446,670$ & $94,392,200.0$ & $100,294,912.0$ & $102,562,886$ \\
government_revenue & 40 & $4,736,260.000$ & $806,464.100$ & $3,978,240$ & $3,978,240$ & $5,415,940$ & $6,393,440$ \\
carbon_social_cost_0 & 40 & 0.000 & 0.000 & 0 & 0 & 0 & 0 \\
carbon_social_cost_120 & 40 & $4,006,452.000$ & $413,632.500$ & $2,924,160$ & $3,702,420$ & $4,359,570$ & $4,685,040$ \\
carbon_social_cost_140 & 40 & $4,674,194.000$ & $482,571.300$ & $3,411,520$ & $4,319,490$ & $5,086,165$ & $5,465,880$ \\
cs_gp_and_gr_minus_sc_0 & 40 & $107,834,537.000$ & $971,653.200$ & $106,594,171$ & $107,321,788.0$ & $108,117,680.0$ & $112,874,320$ \\
cs_gp_and_gr_minus_sc_120 & 40 & $103,828,085.000$ & $1,195,526.000$ & $102,199,171$ & $103,152,691.0$ & $104,240,627.0$ & $109,950,160$ \\
cs_gp_and_gr_minus_sc_140 & 40 & $103,160,343.000$ & $1,242,341.000$ & $101,466,671$ & $102,481,683.0$ & $103,570,938.0$ & $109,462,800$ \\
\hline
\end{tabular}


Table 14: Estimated mean effect on logged genco profits $(\$)$

\begin{tabular}{lcccc}
\hline \hline & TI & TII & ME & MCP \\
& $(1)$ & $(2)$ & $(3)$ & $(4)$ \\
\hline treatment carbon_tax FE & $-1.030^{* * *}$ & $-1.064^{* * *}$ & $-0.981^{* * *}$ & $-0.917^{* * *}$ \\
& $(0.085)$ & $(0.076)$ & $(0.091)$ & $(0.081)$ \\
\hline Seed FE & $\mathrm{X}$ & $\mathrm{X}$ & $\mathrm{X}$ & $\mathrm{X}$ \\
\hline \hline Note: & & & ${ }^{*} \mathrm{p}<0.1 ;{ }^{* *} \mathrm{p}<0.05 ;{ }^{* * *} \mathrm{p}<0.01$
\end{tabular}

Robust standard errors. Note seed fixed effects also serve as year x round fixed effects. Columns represent which "equivalent" cap-and-trade and carbon tax treatments the effect was estimated on. See Table 5 for the exact comparisons.

Table 15: Estimated mean effect on logged CO2 emissions (tonnes)

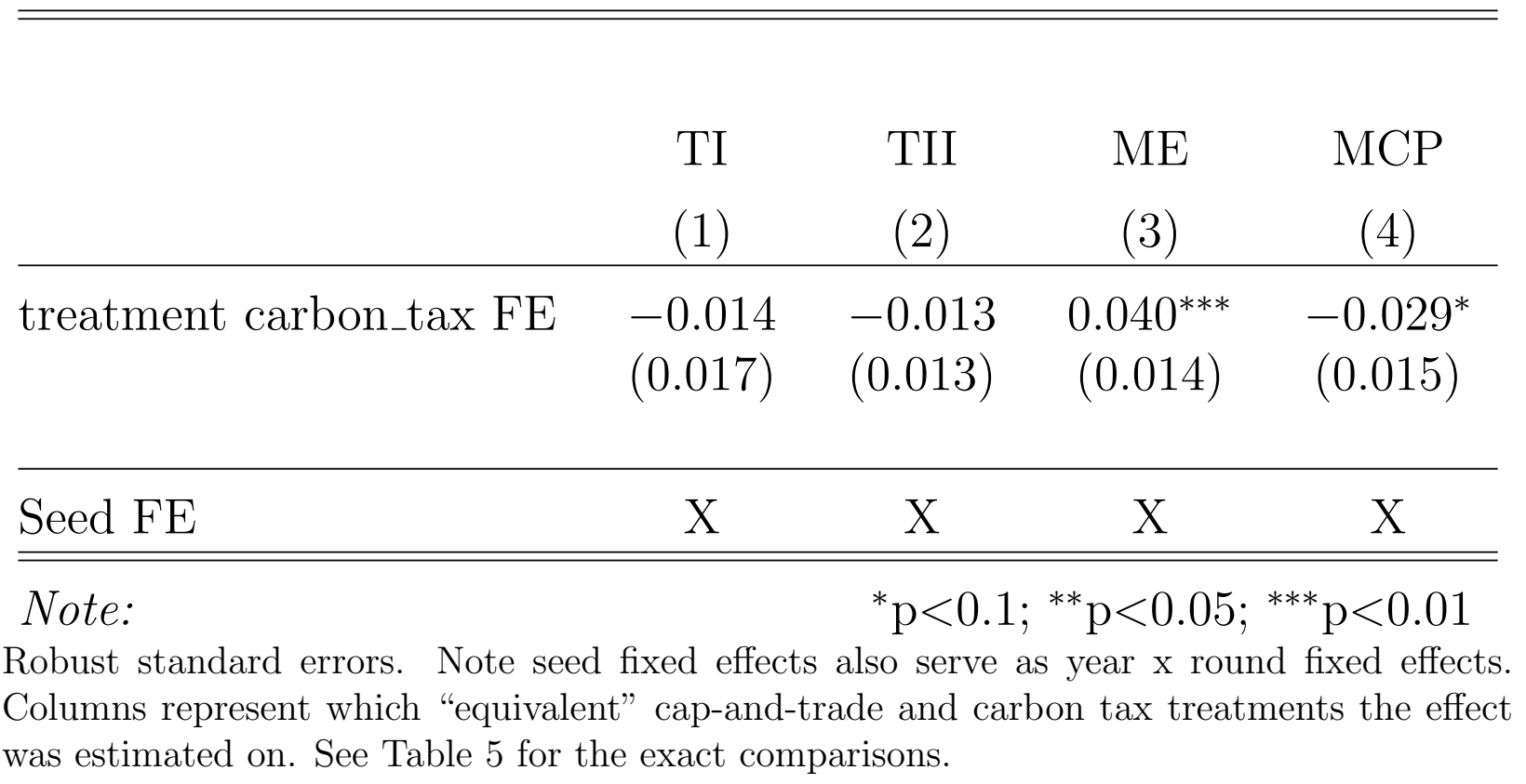


Table 16: Estimated mean effect on logged electricity generation (MWh)

\begin{tabular}{lcccc}
\hline \hline & TI & TII & ME & MCP \\
& $(1)$ & $(2)$ & $(3)$ & $(4)$ \\
\hline treatment carbon_tax FE & $\begin{array}{c}0.028^{* * *} \\
(0.003)\end{array}$ & $\begin{array}{c}0.030^{* * *} \\
(0.002)\end{array}$ & $\begin{array}{c}0.027^{* * *} \\
(0.003)\end{array}$ & $\begin{array}{c}0.025^{* * *} \\
(0.003)\end{array}$ \\
\hline Seed FE & $\mathrm{X}$ & $\mathrm{X}$ & $\mathrm{X}$ & $\mathrm{X}$ \\
\hline \hline Note: & & ${ }^{*} \mathrm{p}<0.1 ;{ }^{* *} \mathrm{p}<0.05 ;{ }^{* * *} \mathrm{p}<0.01$
\end{tabular}

Robust standard errors. Note seed fixed effects also serve as year x round fixed effects. Columns represent which "equivalent" cap-and-trade and carbon tax treatments the effect was estimated on. See Table 5 for the exact comparisons.

Table 17: Estimated mean effect on logged electricity generation (MWh) from Coal and Gas Peaker units

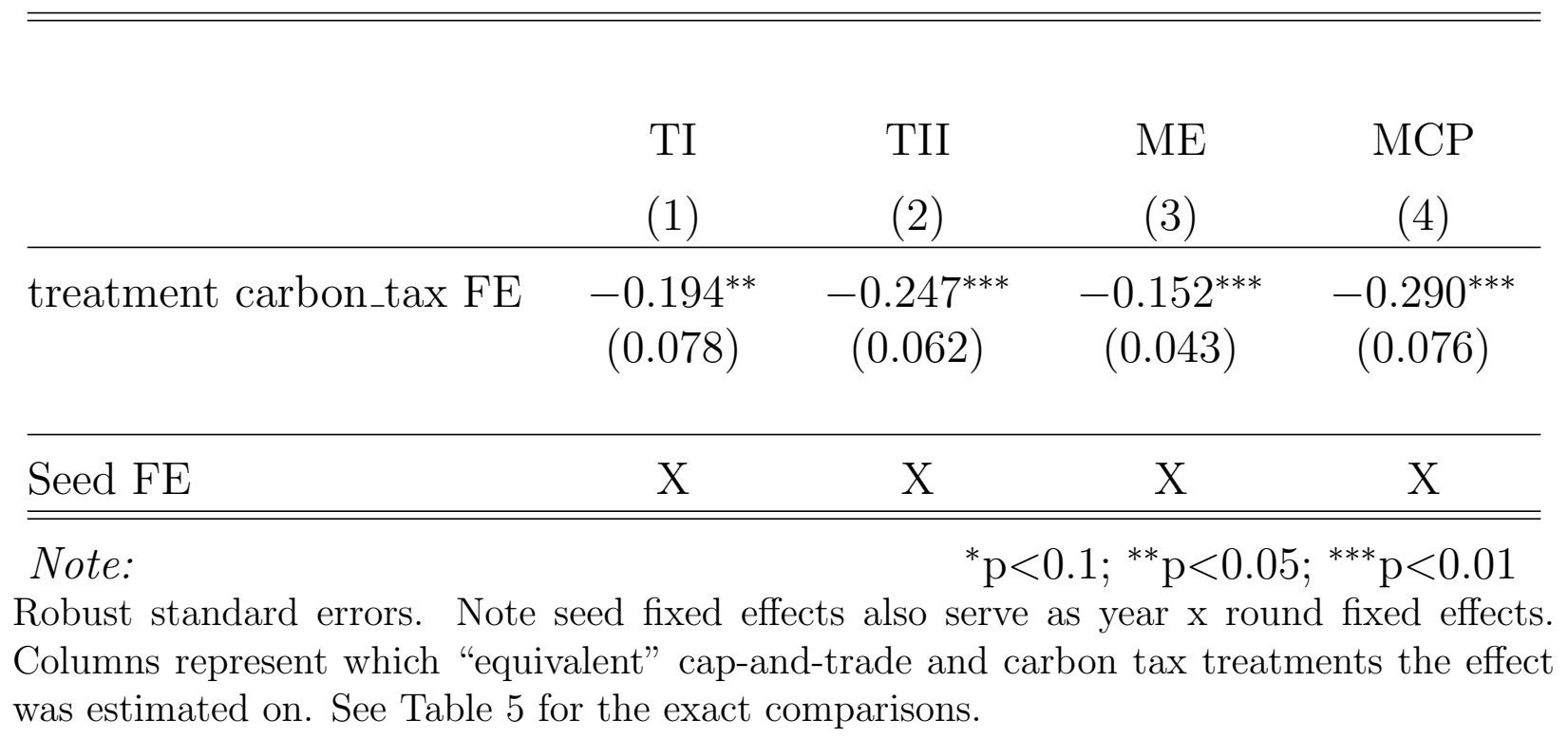


Table 18: Estimated variance effect on assumed carbon prices (Residuals from Table 11)

\begin{tabular}{lcccc}
\hline \hline & & & & \\
& TI & TII & ME & MCP \\
& $(1)$ & $(2)$ & $(3)$ & $(4)$ \\
\hline treatment carbon_tax FE & $-81.414^{* * *}$ & $-80.266^{* * *}$ & $-77.260^{* * *}$ & $-73.125^{* * *}$ \\
& $(2.972)$ & $(2.932)$ & $(5.351)$ & $(2.975)$ \\
& & & & \\
\hline Seed FE & $\mathrm{X}$ & $\mathrm{X}$ & $\mathrm{X}$ & $\mathrm{X}$ \\
Period FE & $\mathrm{X}$ & $\mathrm{X}$ & & $\mathrm{X}$ \\
Player FE & $\mathrm{X}$ & $\mathrm{X}$ & $\mathrm{X}$ & $\mathrm{X}$ \\
\hline \hline Note: & & & & ${ }^{*} \mathrm{p}<0.1 ;{ }^{* *} \mathrm{p}<0.05 ;{ }^{* * *} \mathrm{p}<0.01$
\end{tabular}

Robust standard errors. Note seed fixed effects also serve as year x round fixed effects. Columns represent which "equivalent" cap-and-trade and carbon tax treatment the effect was estimated on. See Table 5 for the exact comparisons. We do not include a Period fixed effect for the ME assumed carbon price regression since in the 2016 version of the experiment we did not record assumed carbon prices for periods 1,2 , and 3

Table 19: Estimated mean effect on logged consumer surplus (\$)

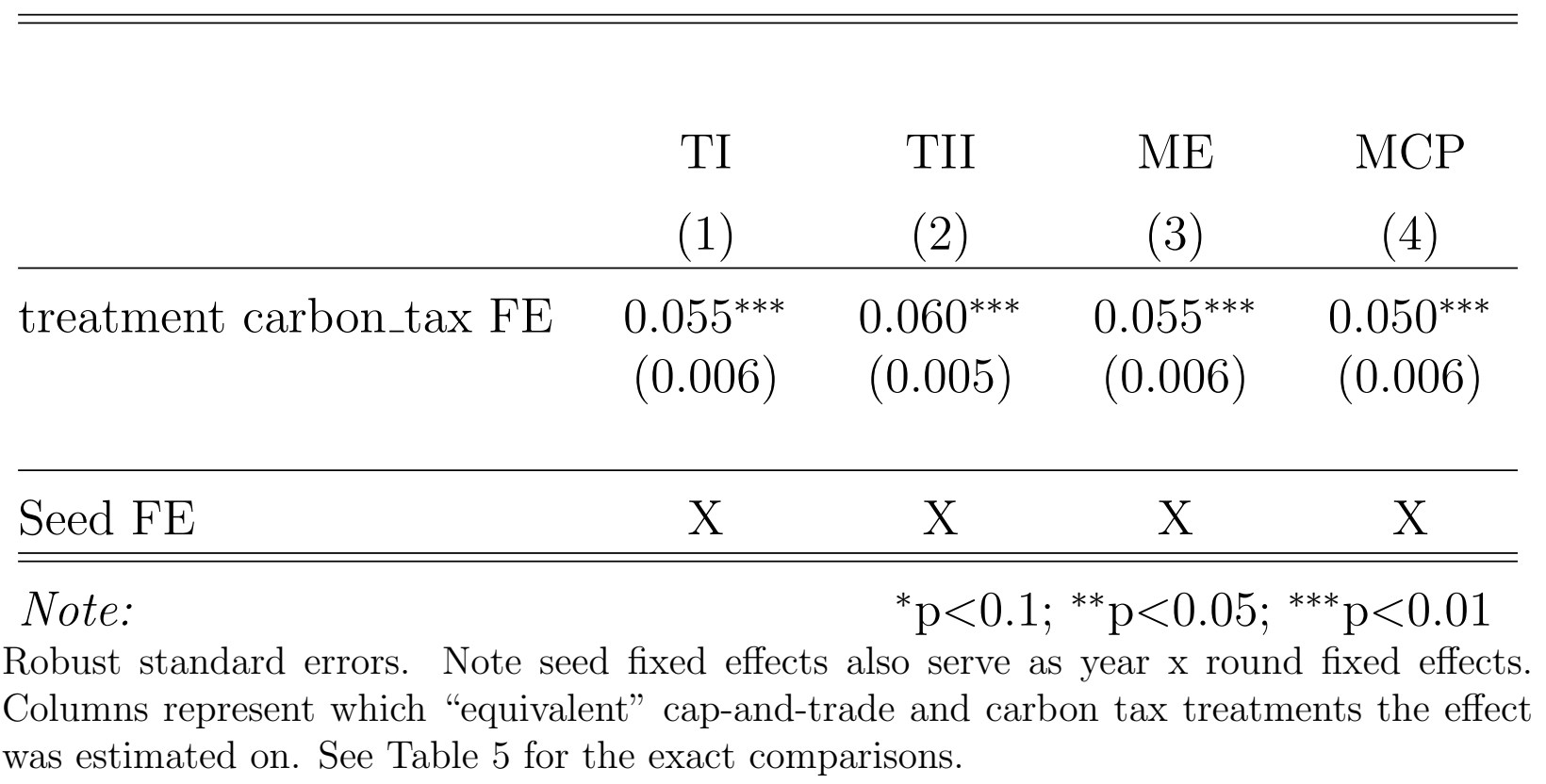


Table 20: Estimated mean effect on logged government revenue $(\$)$

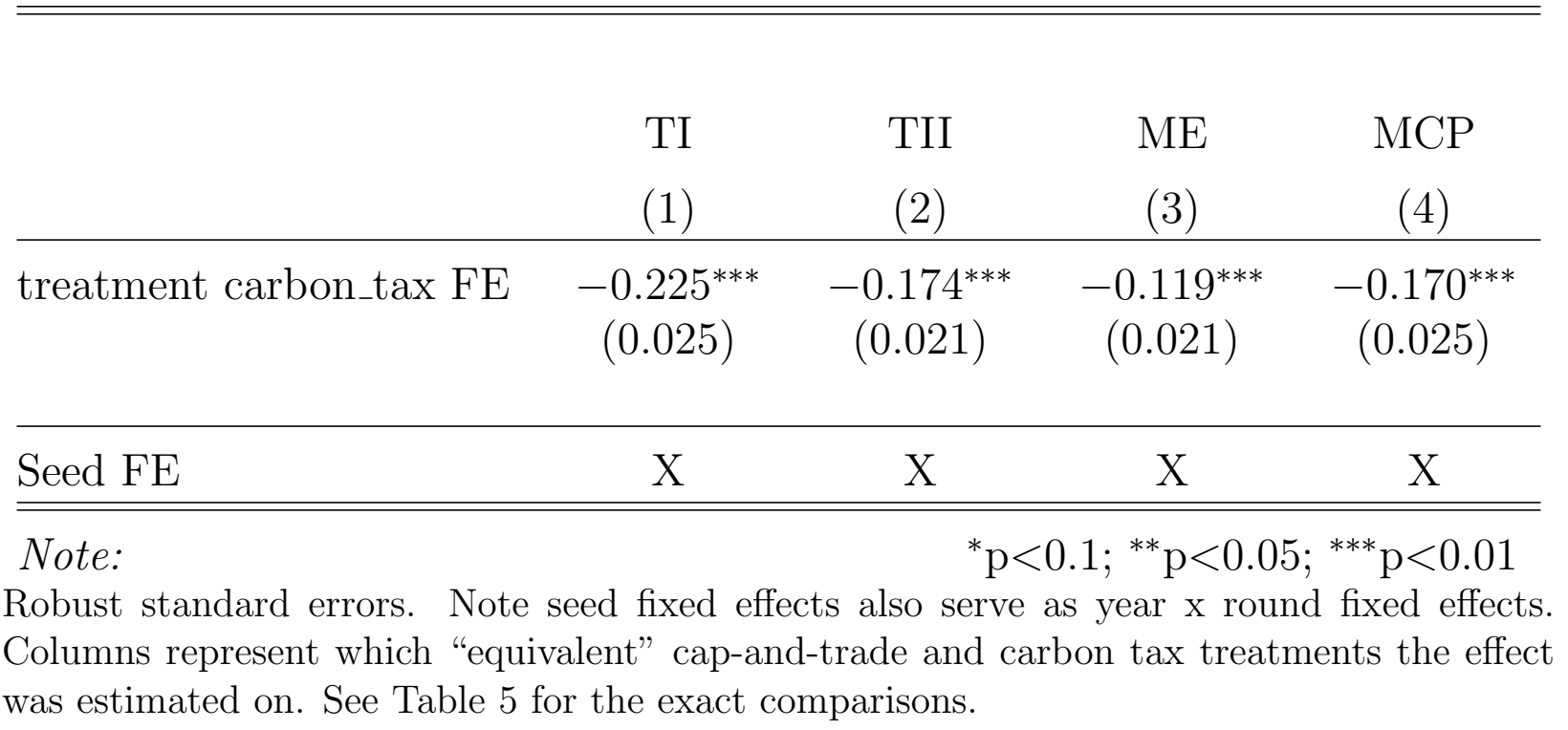


Figure 1: Schematic illustrating carbon price and abatement quantity under a hypothetical carbon pricing policy.

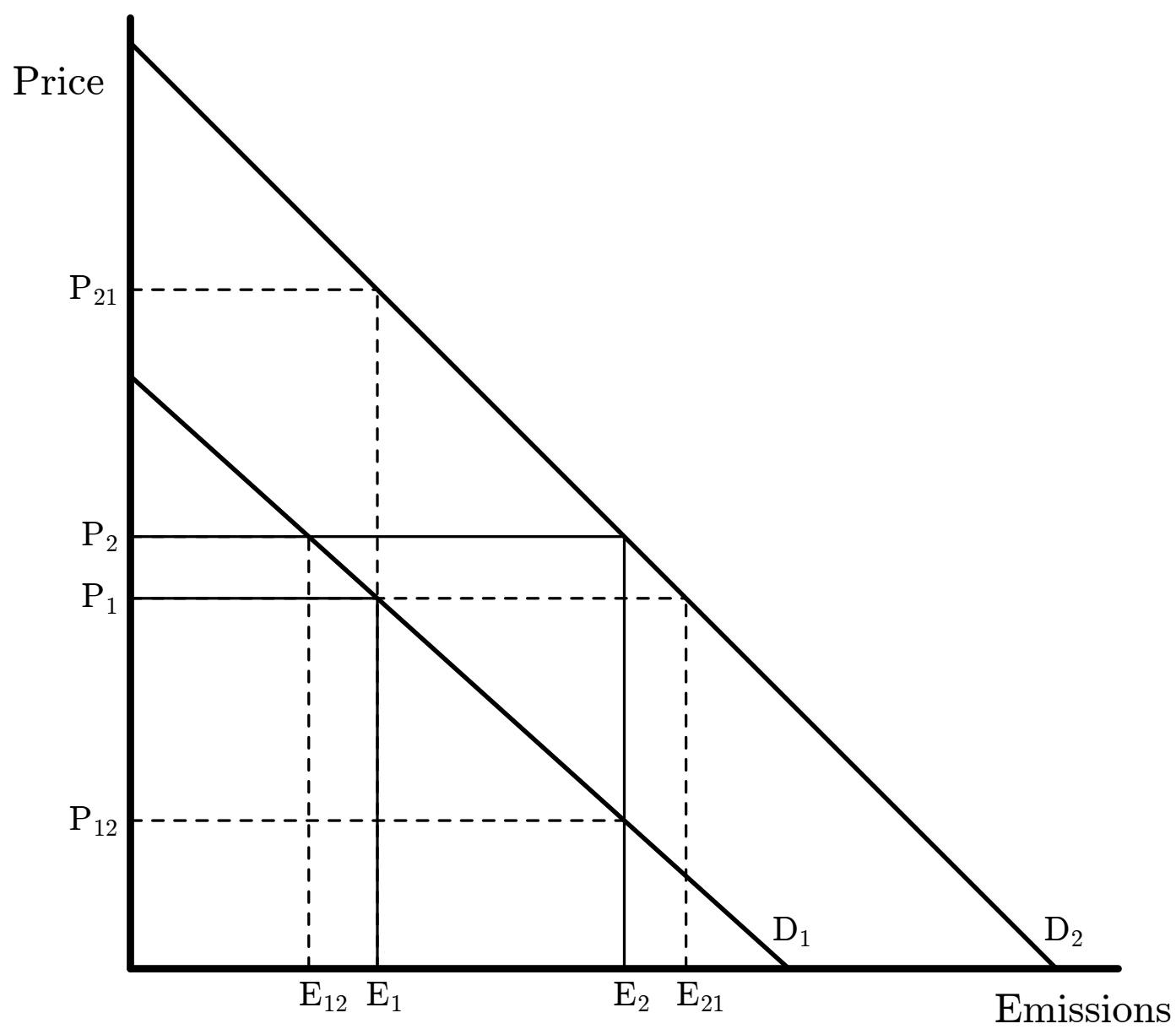


Figure 2: Annotated screenshot of the wholesale electricity market uniform-price auction price offer interface.

\section{"Place Bids": Bid into Electricity Market}

Entering a carbon price and clicking "recompute bids with carbon price" sets the bids of all plants in all periods to their marginal costs incorporating that carbon price

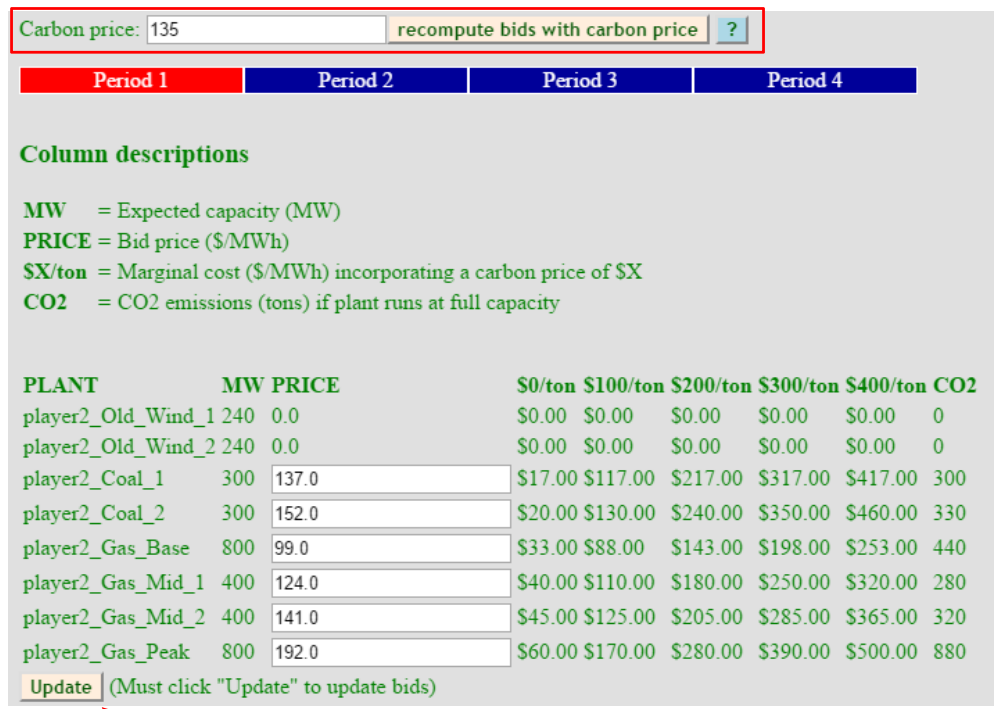


Figure 3: Histogram of output per wind unit in a period. Distribution is normal with $\mu=240$ MWh and $\sigma=96 \mathrm{MWh}$, censored to 0-960 MWh.

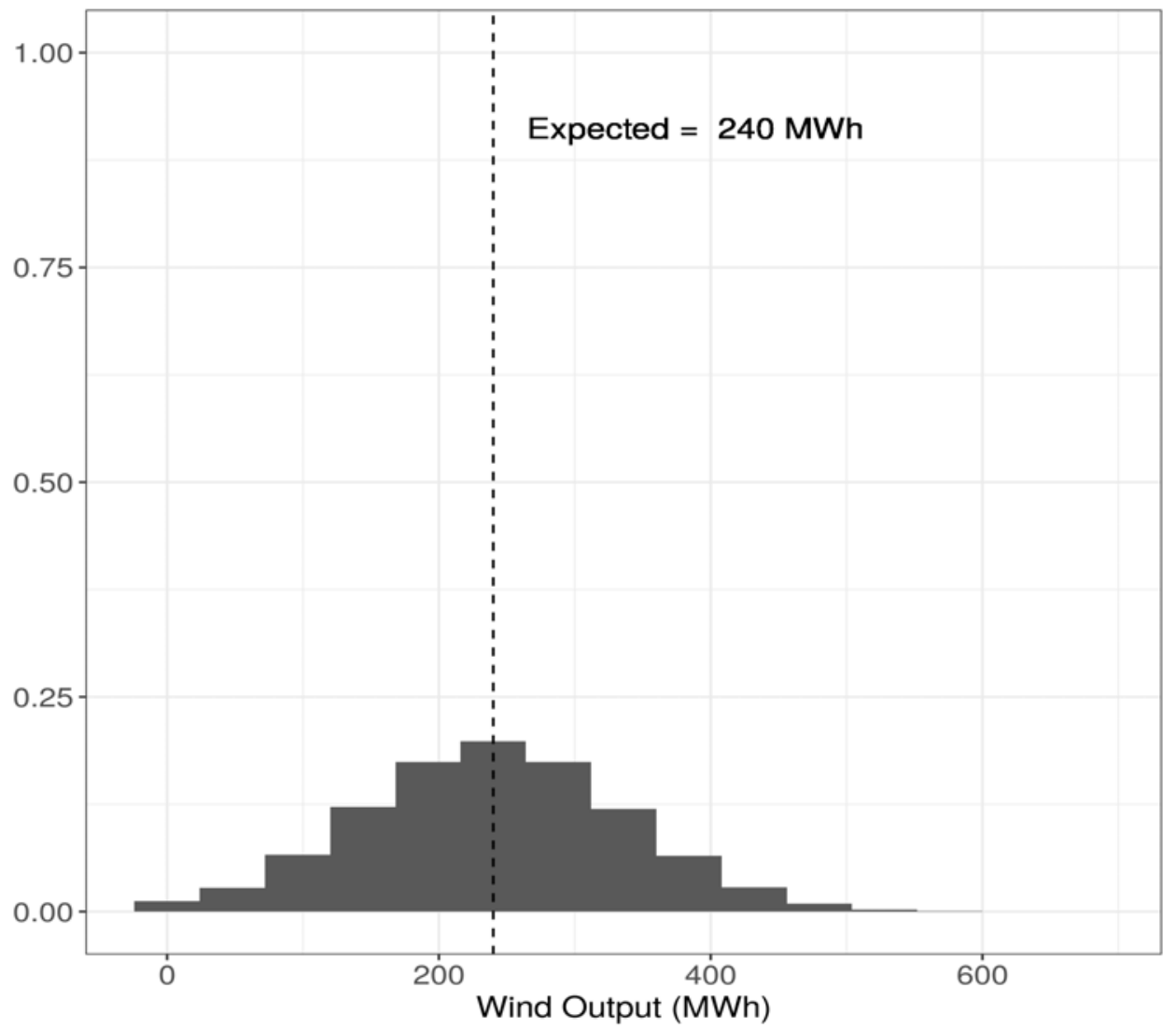


Figure 4: Annotated screenshot of wholesale-electricity-market figure provided for each period showing the demand curve, supply curve (color coded by player), and the market clearing price.

\section{Electricity Market Chart}

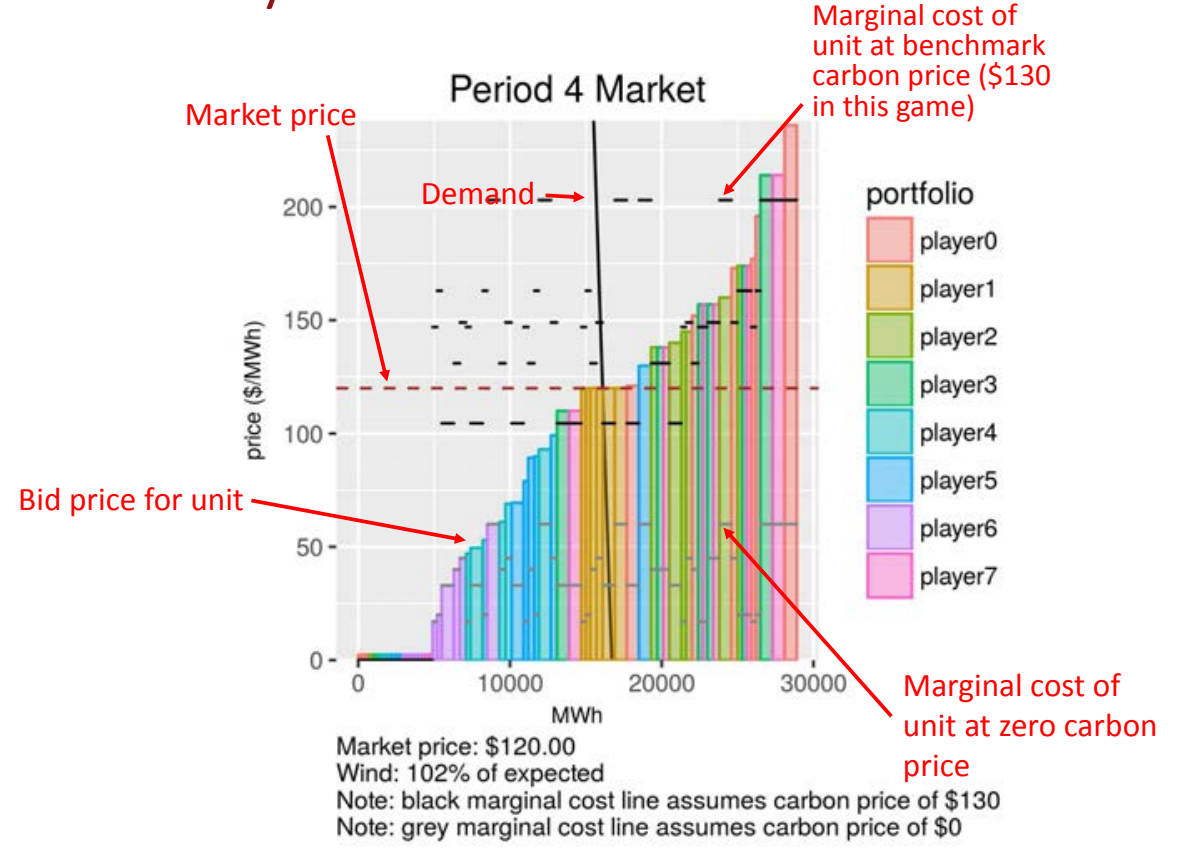


Figure 5: Example period 1 electricity market results
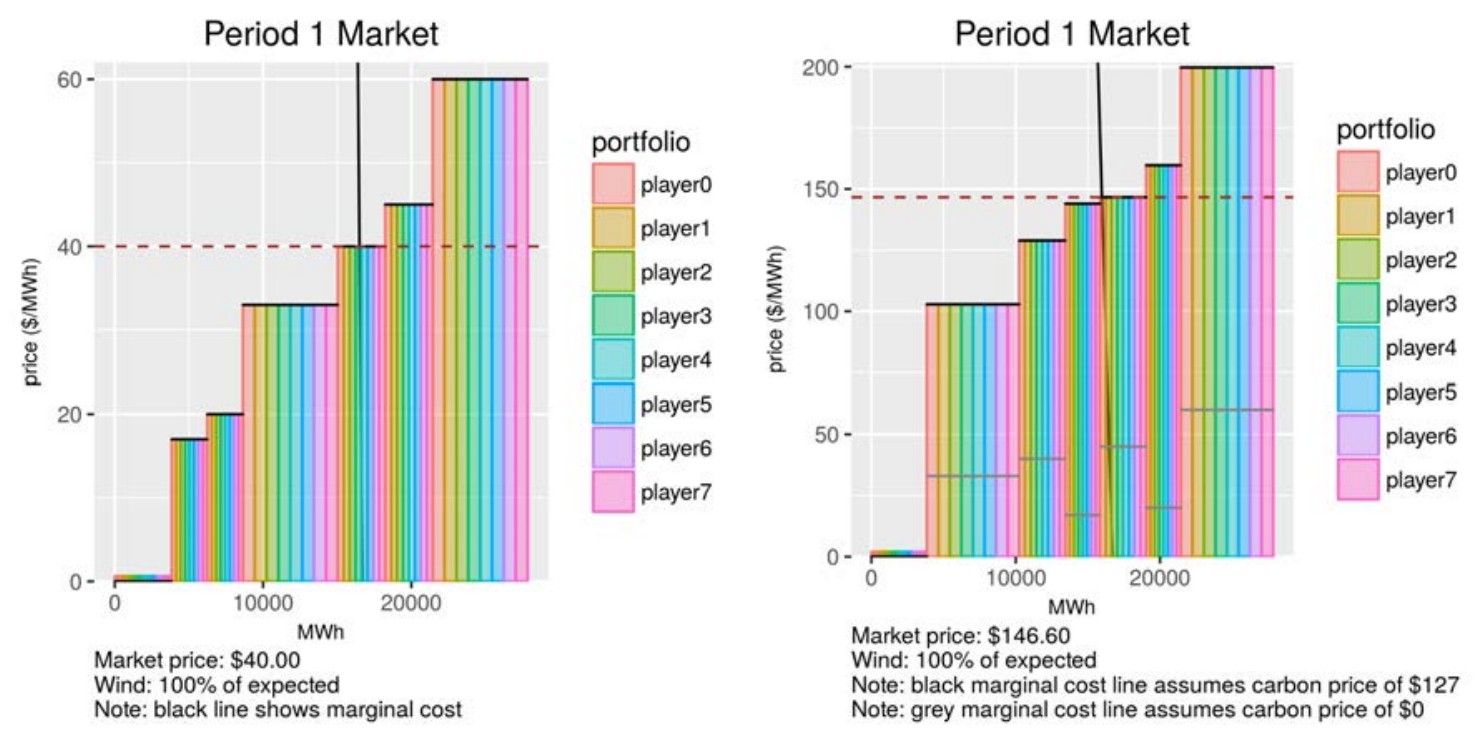

Note: Assuming marginal cost pricing (left assuming carbon cost of $\$ 0 /$ tonne and right assuming $\$ 127 /$ tonne). 
Figure 6: Wind generation units

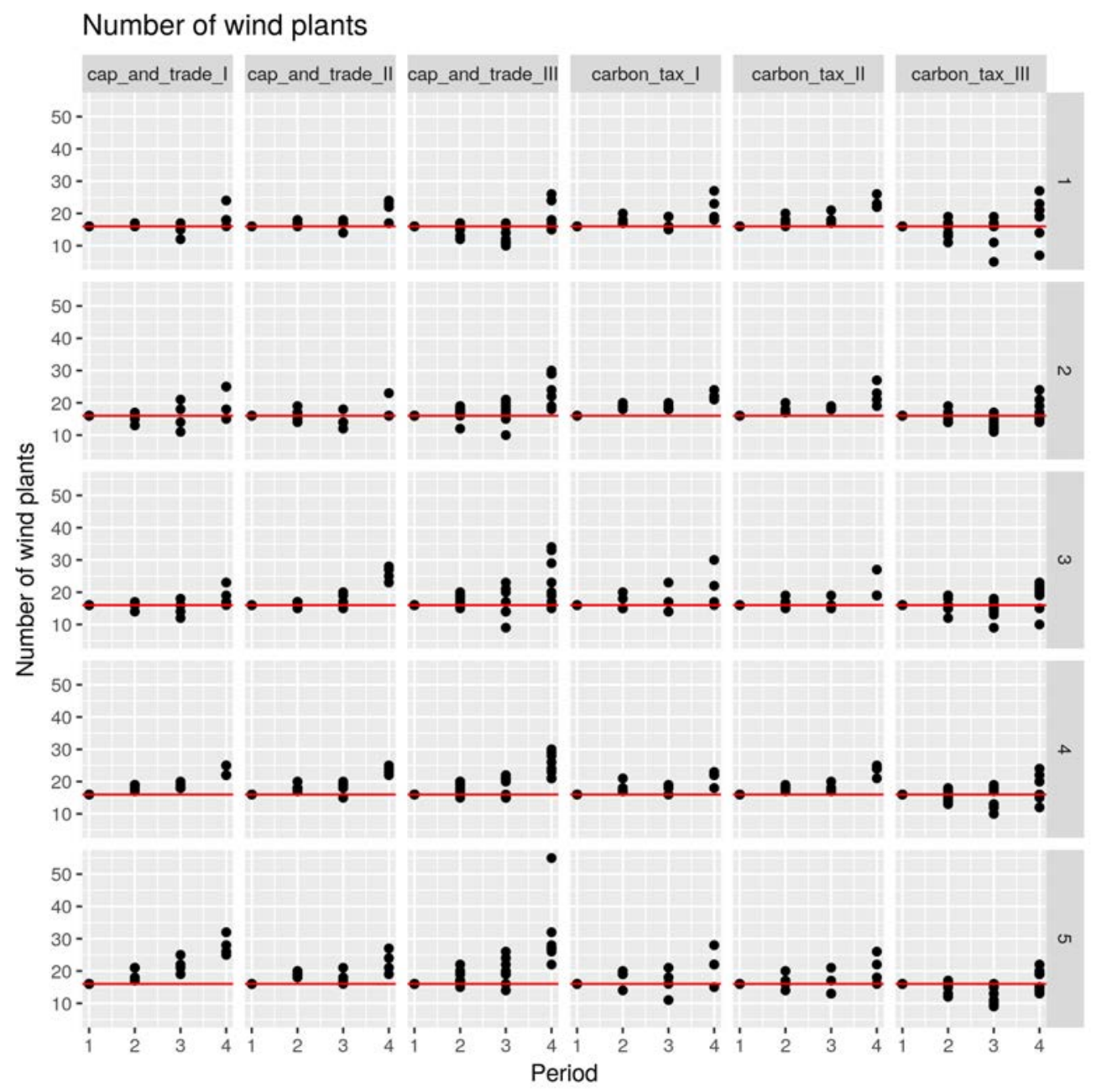

Note: Columns are treatments "Cap I", "Cap II", "Cap III", "Tax I", "Tax II", "Tax III" and rows are round of games $1,2,3,4,5$. The red line is our initial wind generation units of sixteen. 
Figure 7: The relationship of carbon prices on $\mathrm{CO}_{2}$ emissions and wholesale electricity market prices

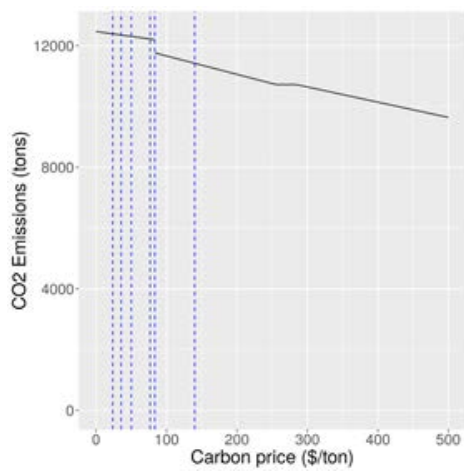

(a) 0 MWh of Wind

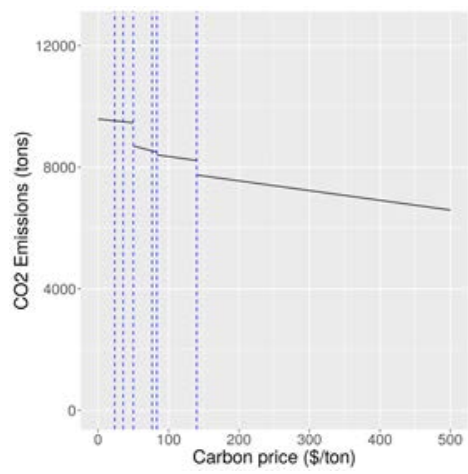

(c) 3,840 MWh of Wind

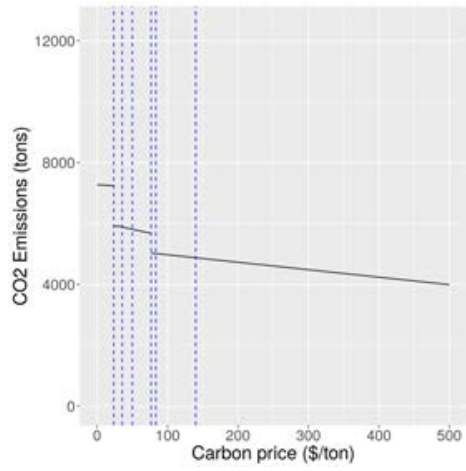

(e) 7,680 MWh of Wind

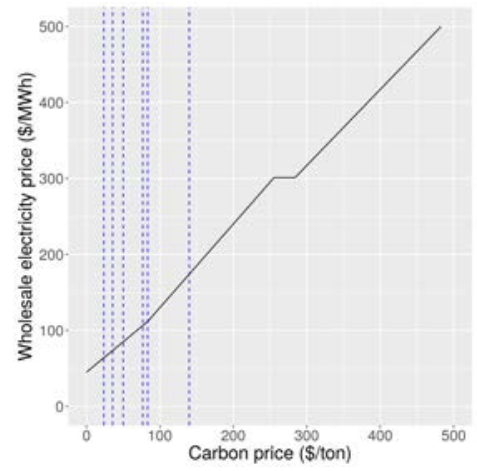

(b) 0 MWh of Wind

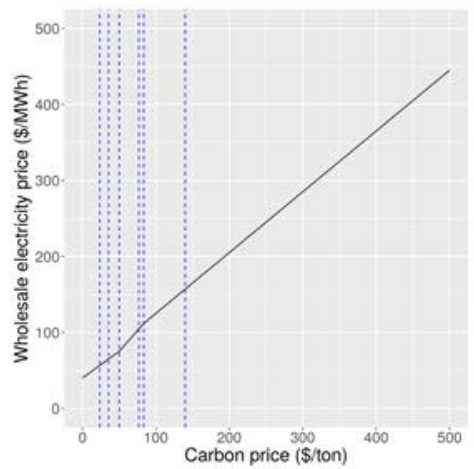

(d) 3,840 MWh of Wind

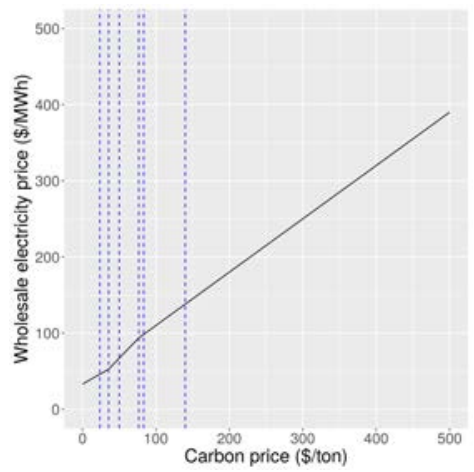

(f) 7,680 MWh of Wind

Note: Left column is $\mathrm{CO}_{2}$ emissions and right column is wholesale electricity market prices. Rows are different realizations of wind: $0 \mathrm{MWh}, 3,840 \mathrm{MWh}$, and 7,680 MWh. Assumes marginal cost pricing. Dashed vertical lines are carbon prices which cause merit order shifts in the supply curve. 
Figure 8: Histogram of emissions given a carbon tax of $\$ 127.00 /$ tonne

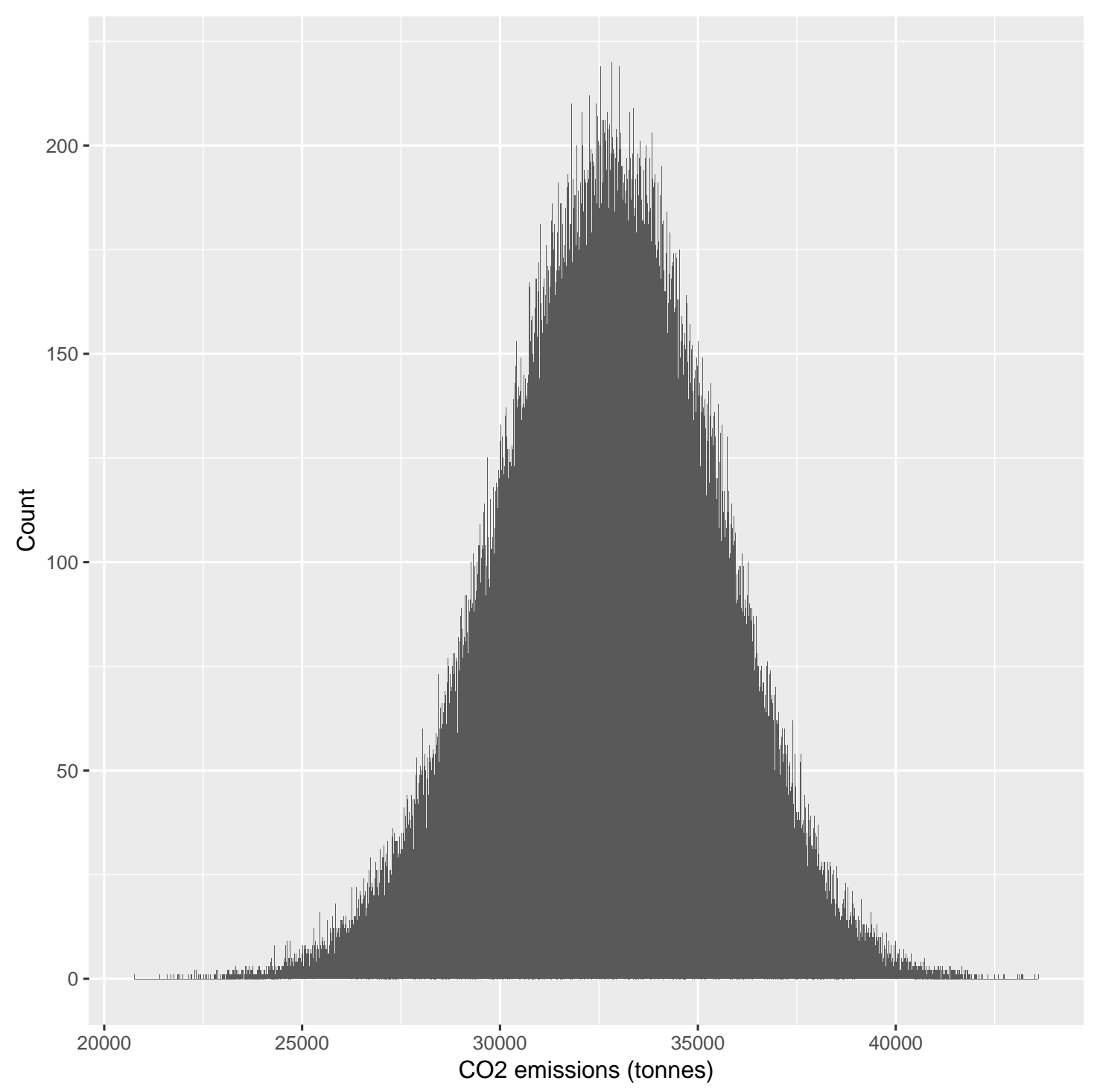

Note: Assumes each gencos holds two wind units and prices at marginal cost incorporating a carbon tax of $\$ 127 /$ tonne. The mean is 32,697 tonnes $\mathrm{CO}_{2}$. 
Figure 9: Histogram of carbon prices needed to meet carbon cap

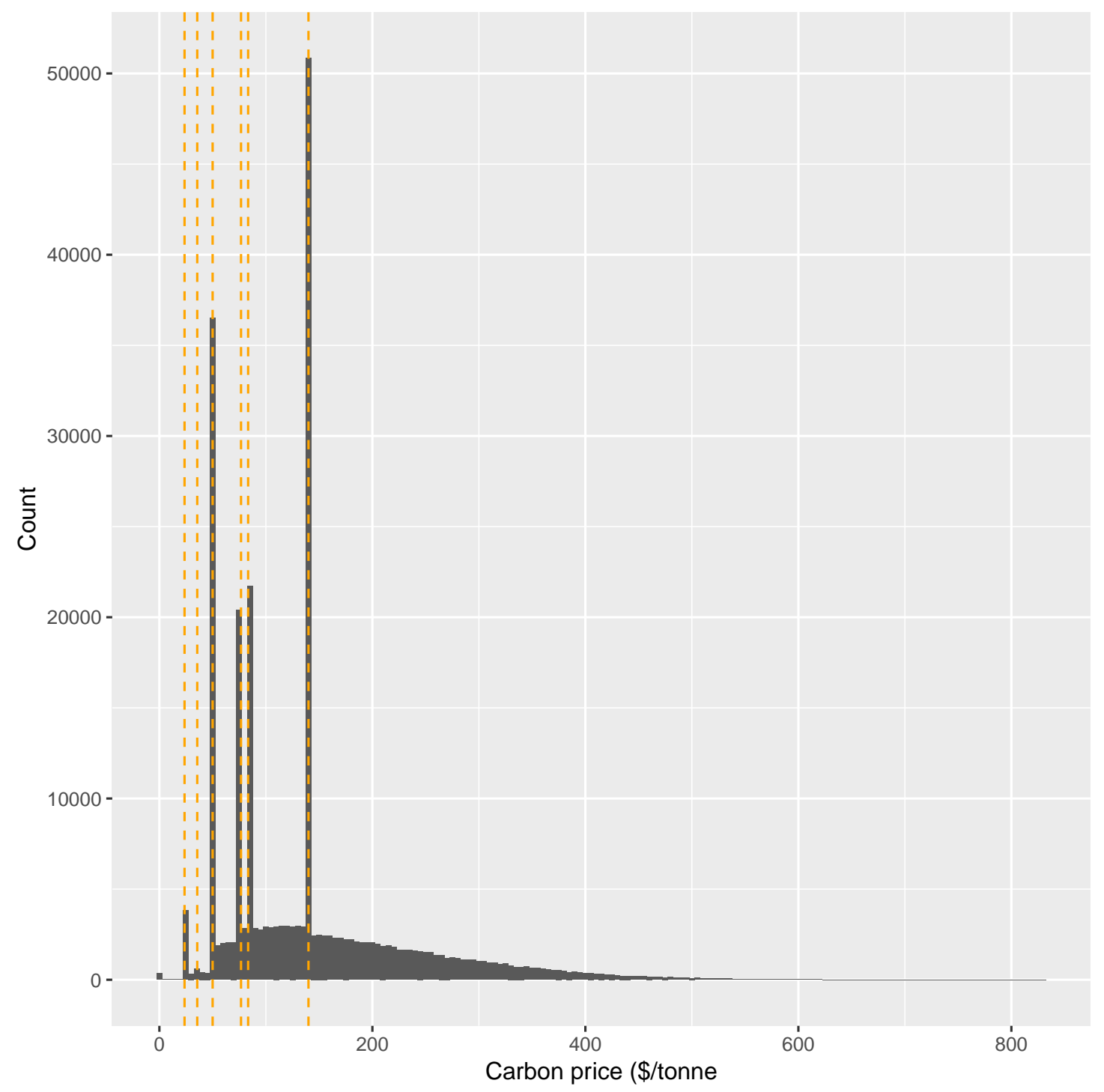

Note: Assumes that the social planner has perfect knowledge of future game wind realizations and that for each game (and related set of wind realizations) the social planner sets one carbon price in order for the $\mathrm{CO}_{2}$ emissions to be (weakly) less than 32,697 tonnes. Assumes each gencos holds two wind units and prices at marginal cost. The orange dashed lines are the carbon prices which cause merit order shifts. The mean is $\$ 136.21$. 
Figure 10: Wholesale electricity prices

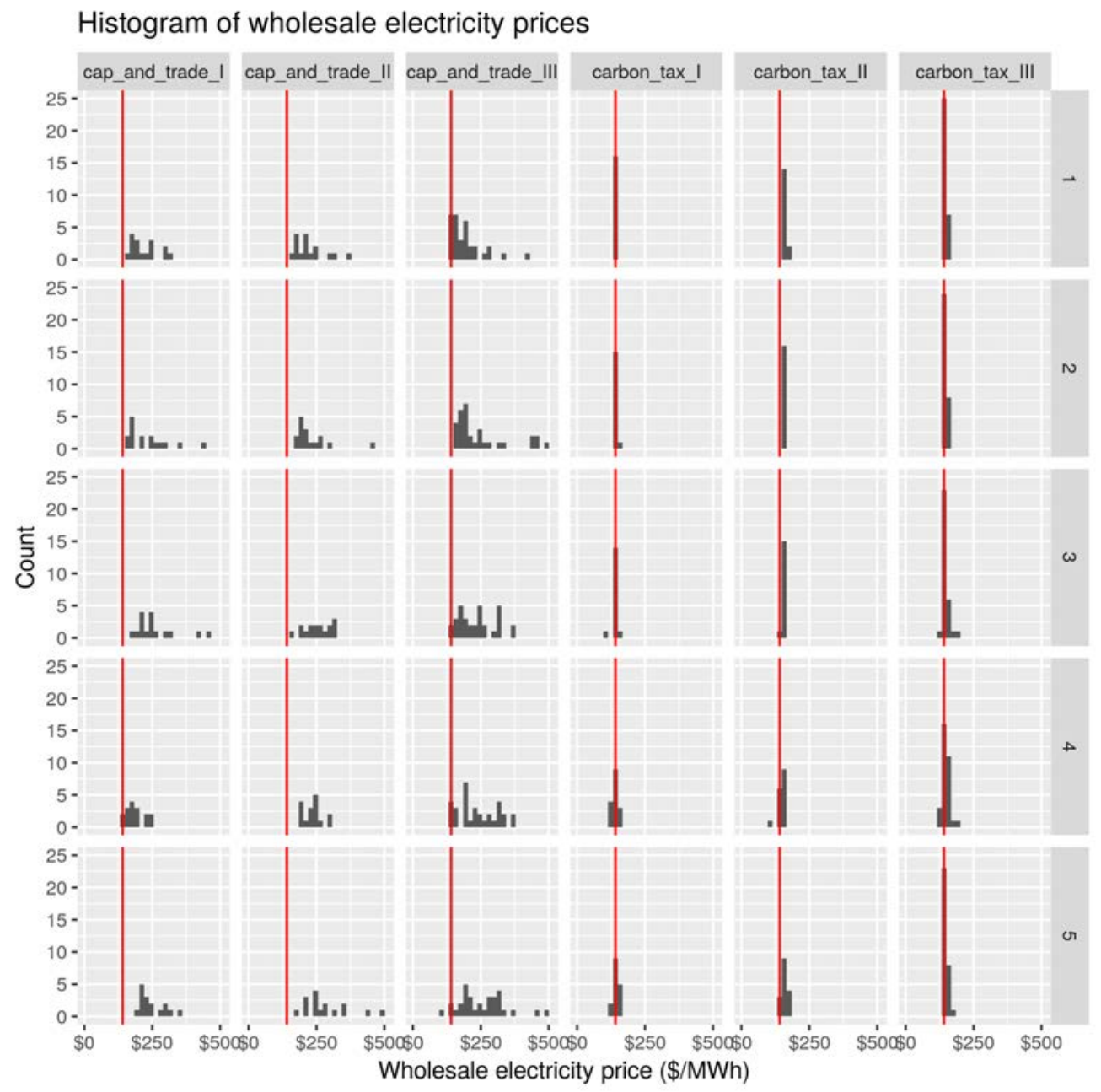

Note: Columns are treatments "Cap I", "Cap II", "Cap III", "Tax I", "Tax II", "Tax III" and rows are round of games $1,2,3,4,5$. The red line is $\$ 141$ which is the market price we would observe with 16 wind generation units producing at mean output and all non-renewable generation units offer prices at marginal cost assuming a carbon price of $\$ 120$. 
Figure 11: Assumed carbon prices

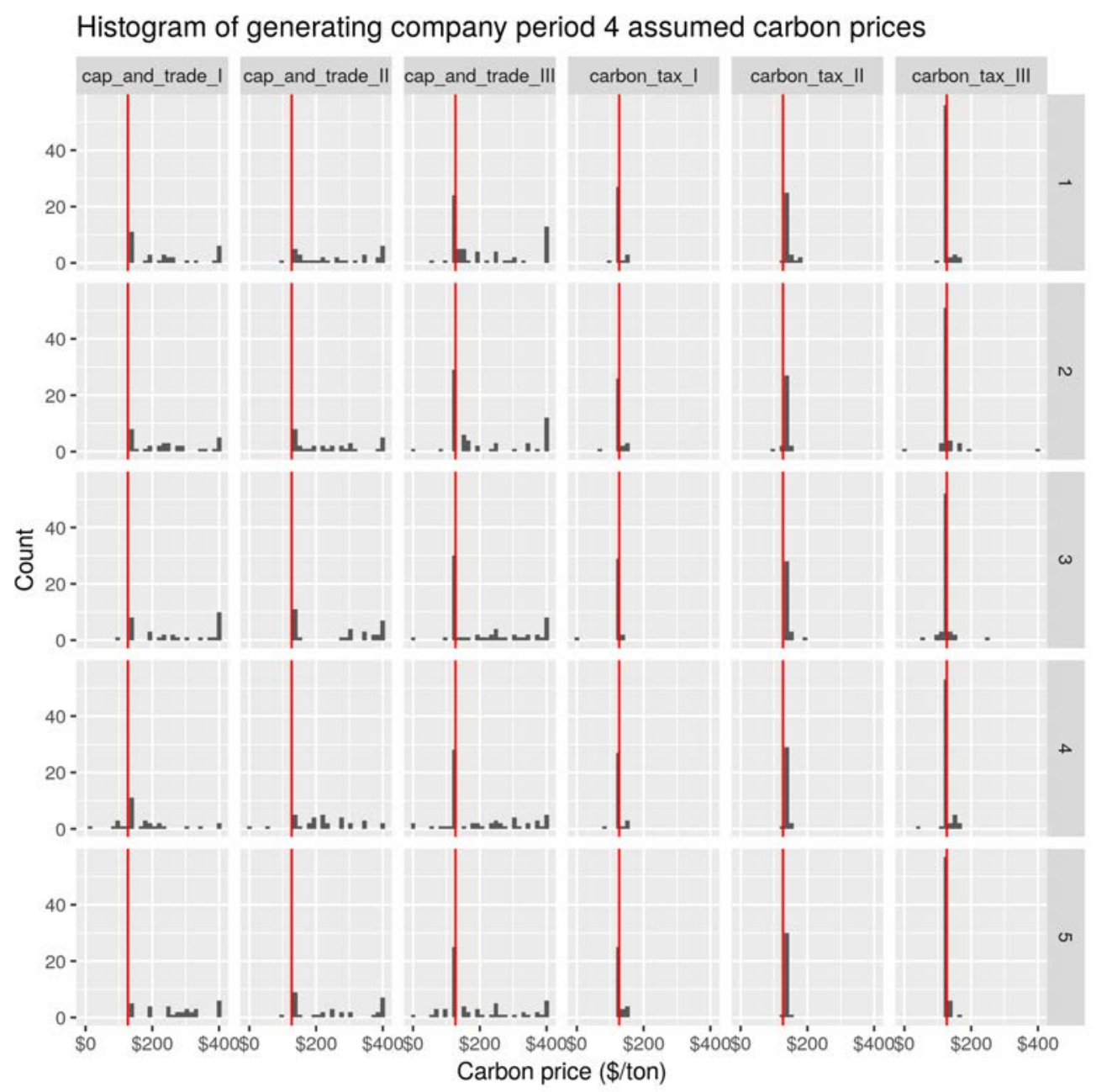

Note: Columns are treatments "Cap I", "Cap II", "Cap III", "Tax I", "Tax II", "Tax III" and rows are round of games $1,2,3,4,5$. The red line is at $\$ 120$. 
Figure 12: Genco profits

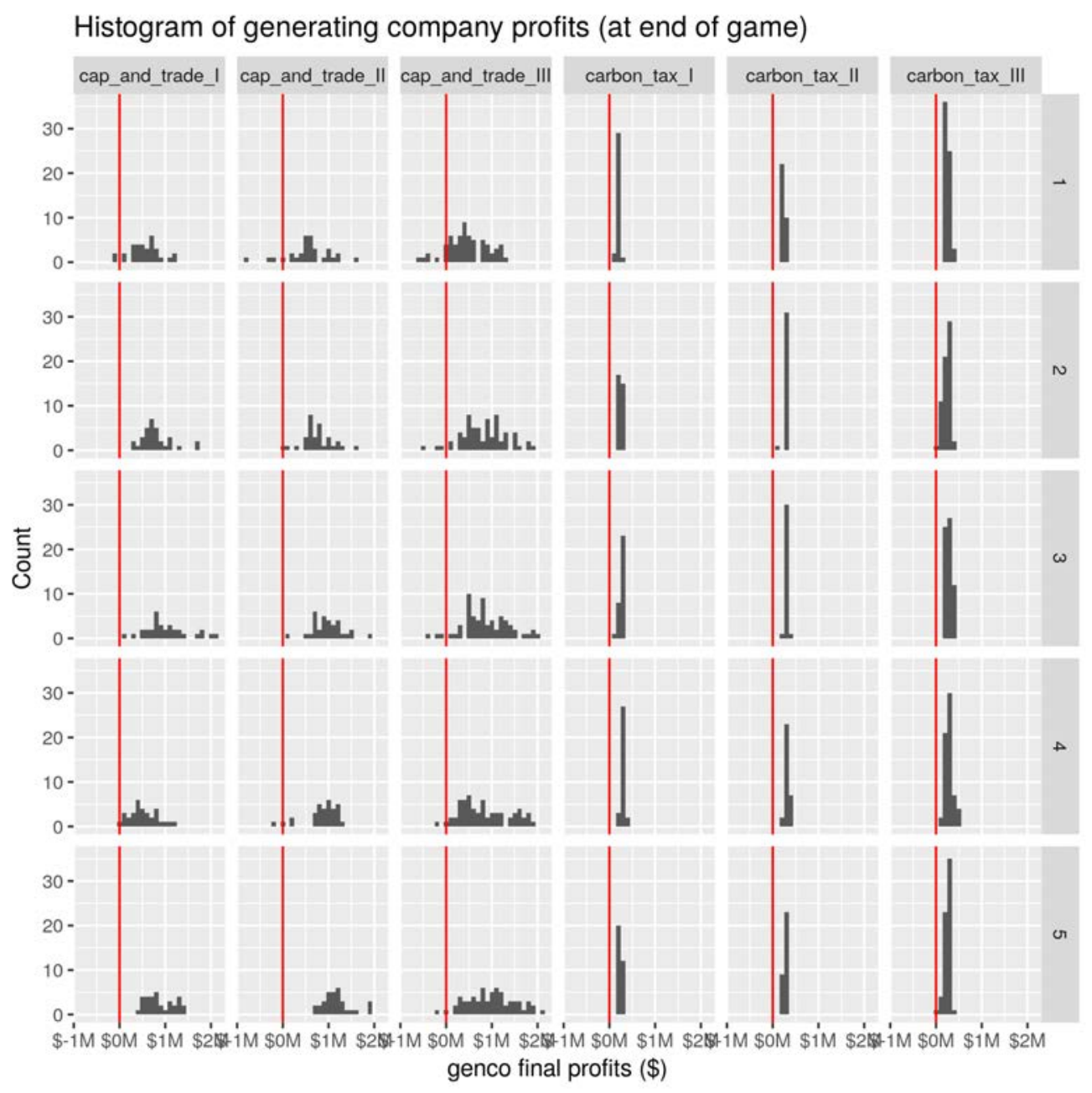

Note: Columns are treatments "Cap I", "Cap II", "Cap III", "Tax I", "Tax II", "Tax III" and rows are round of games $1,2,3,4,5$. The red line is $\$ 0$. 
Figure 13: Standard deviations of assumed carbon prices

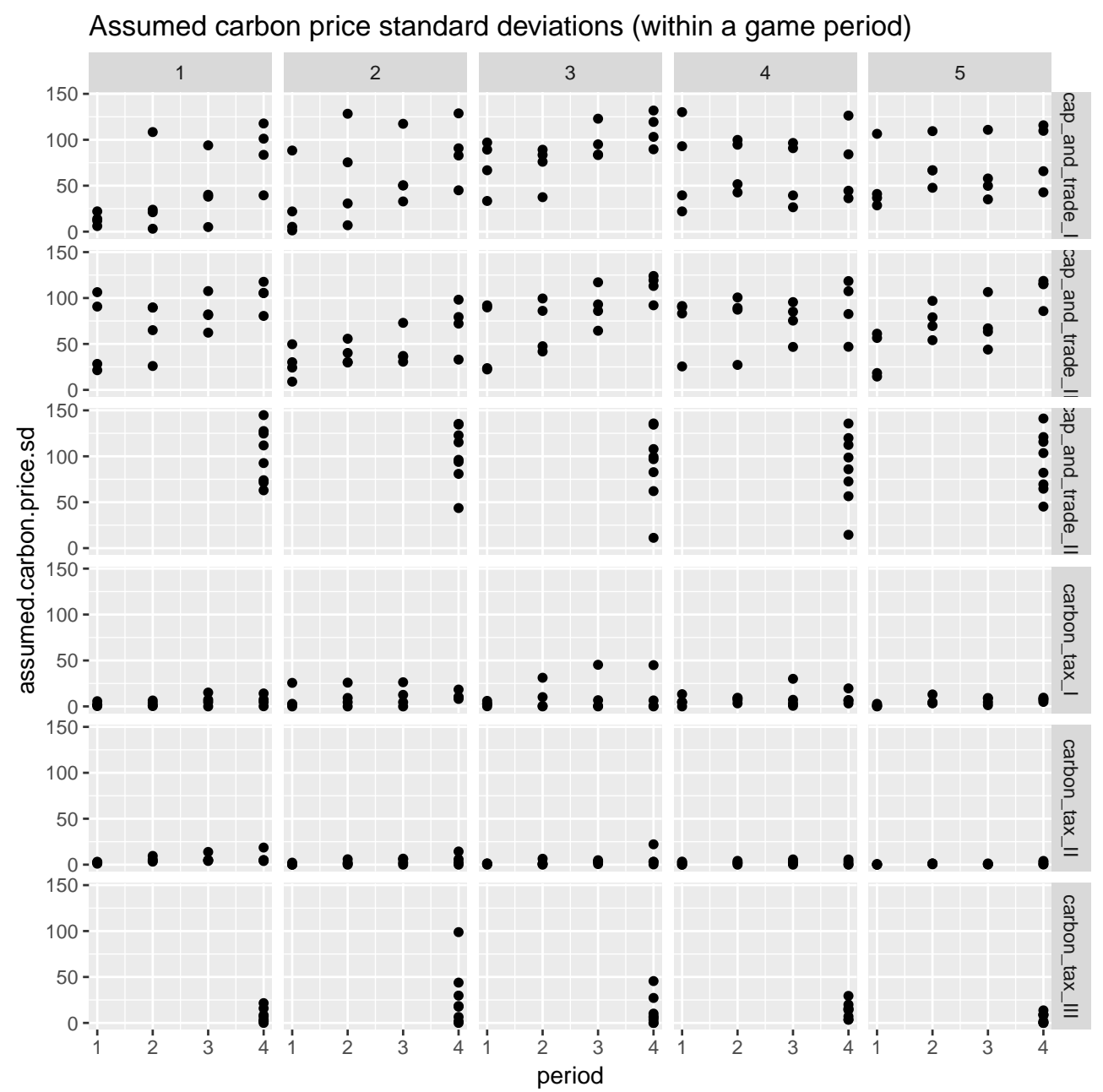

Note: Within-period standard deviations in assumed carbon price by treatment, period (1-4), and game round (1-5). Data for periods 1-3 was not recorded for the Cap III and Tax III treatments. 
Figure 14: Simulated effect of carbon price disagreement on generation costs in our fourperiod cap-and-trade game

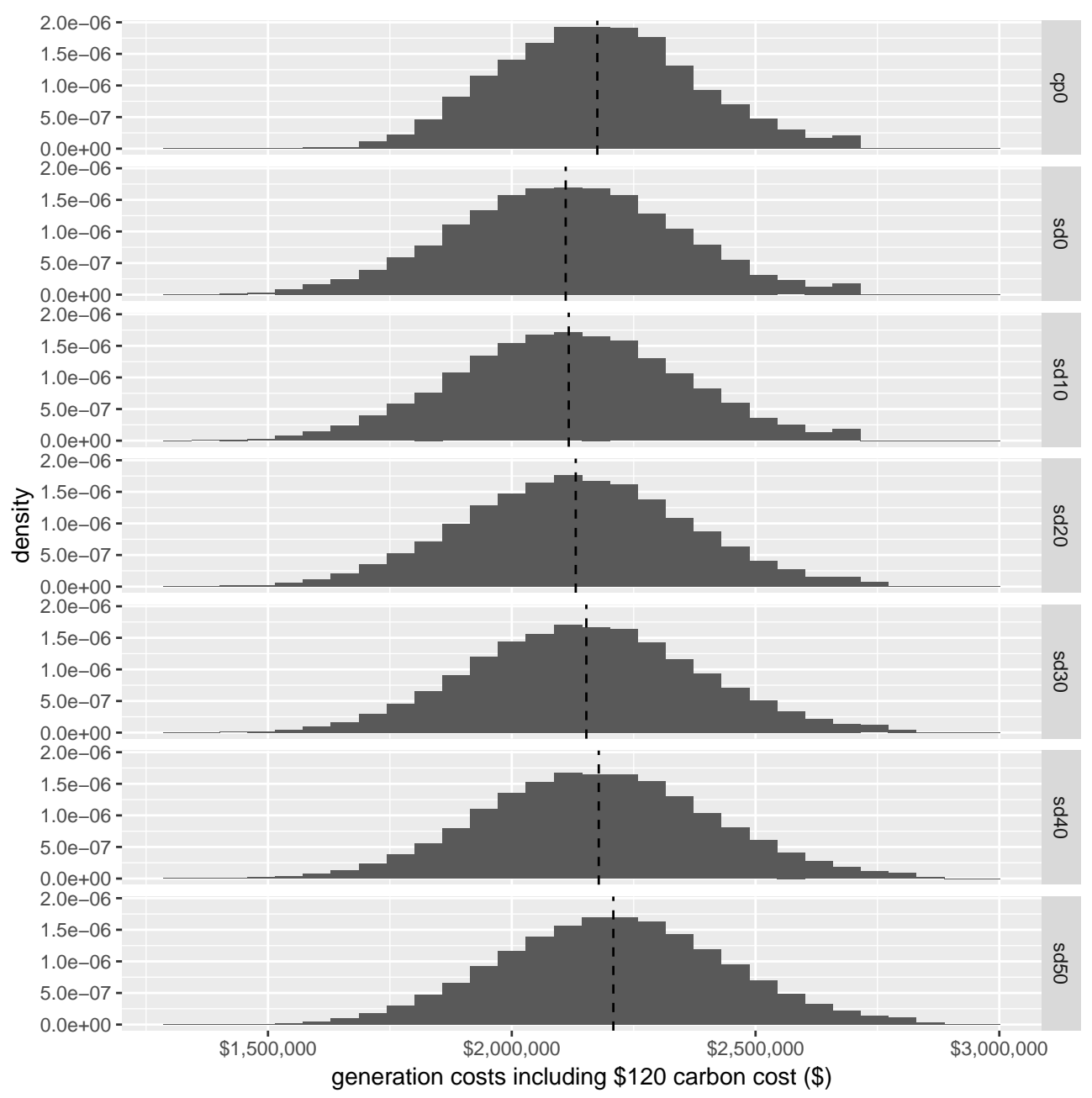

Note: The top chart ("cp0") shows the probability density function for absolute generation costs in simulated game runs assuming a carbon price of $\$ 0$, marginal cost pricing, and 16 wind generation units. The other charts ("sd0"-"sd50") show probability density functions for the generation costs in simulated game runs (assuming marginal cost pricing and 16 wind generation units) as the variance in assumed carbon prices between players is increased from a standard deviation of $\$ 0 /$ tonne $\mathrm{CO}_{2}$ to $\$ 50 /$ tonne $\mathrm{CO}_{2}$. 
Figure 15: Within-period means of assumed carbon price by treatment, period (1-4), and game round (1-5)

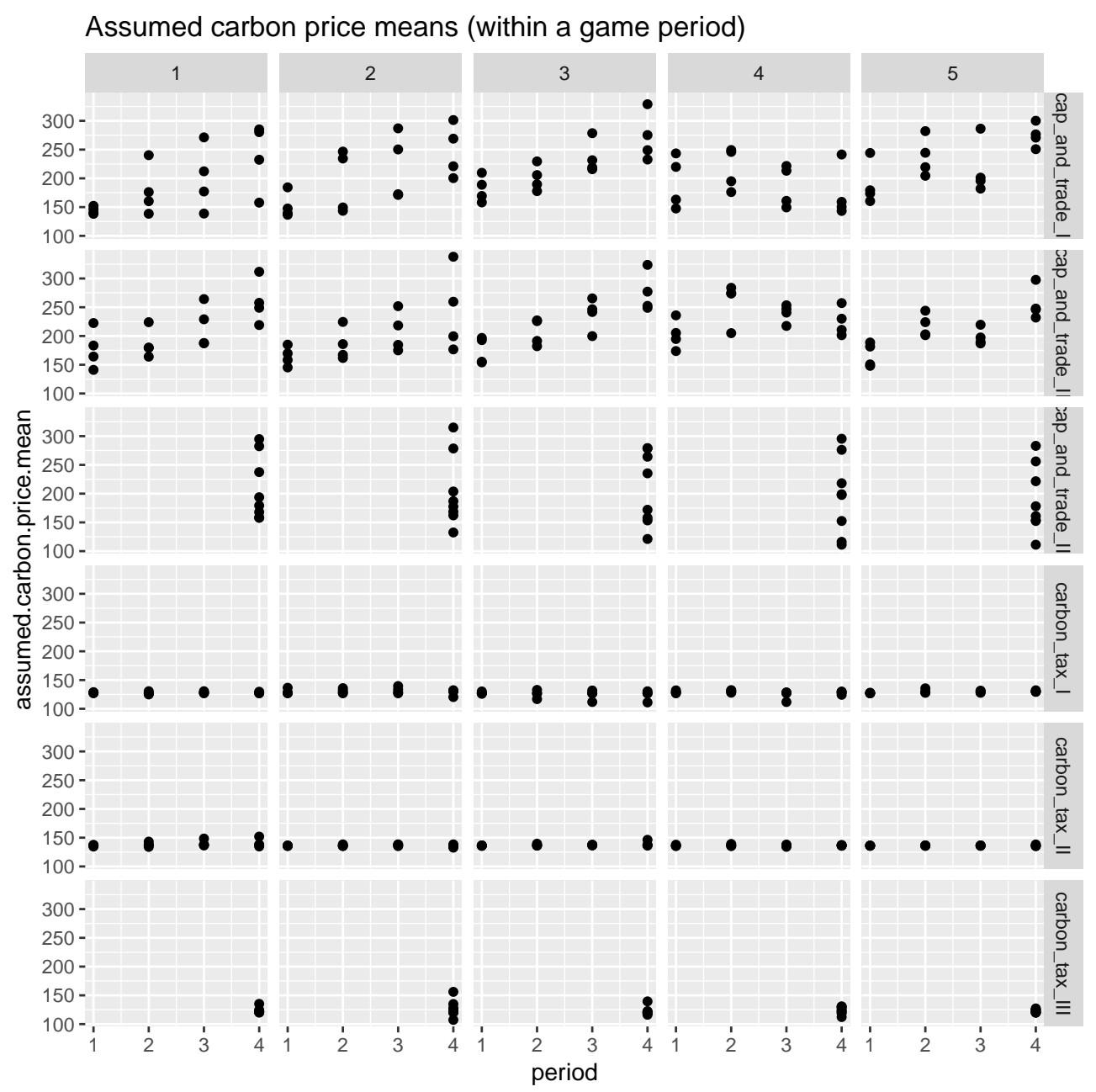

Note: These are the prices that were factored into players' wholesale electricity market price offers. Data for periods 1-3 was not recorded for the Cap III and Tax III treatments. 
Figure 16: Volume-weighted average traded carbon prices by period in each cap-and-trade game

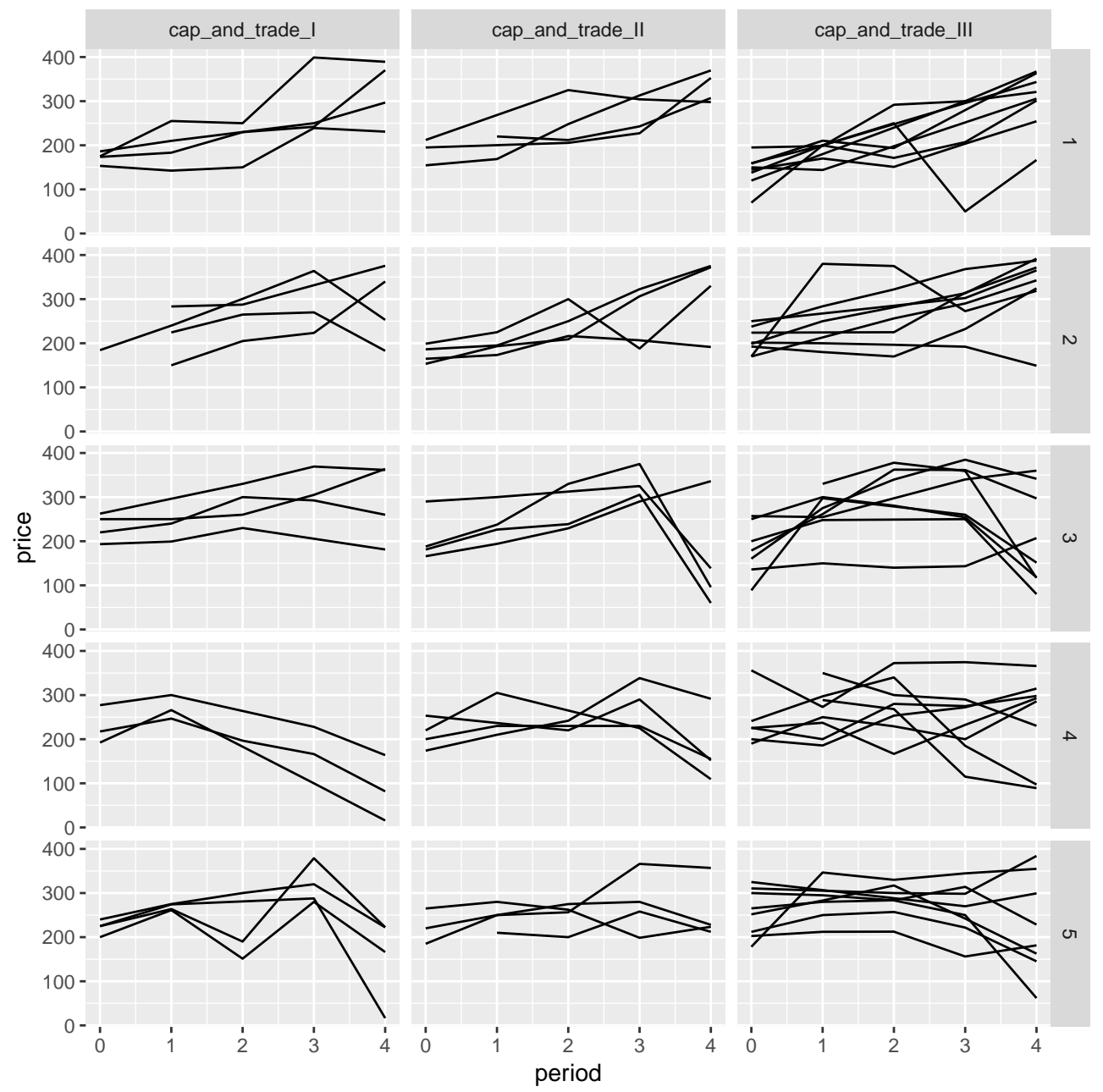

Note: Periods 1-4 are the trading periods before the respective electricity market periods; period 5 is the final trading period before assessment of any non-compliance penalties. 
Figure 17: Within-period values of assumed carbon price for each player by treatment, period (1-4), and game round (1-5)

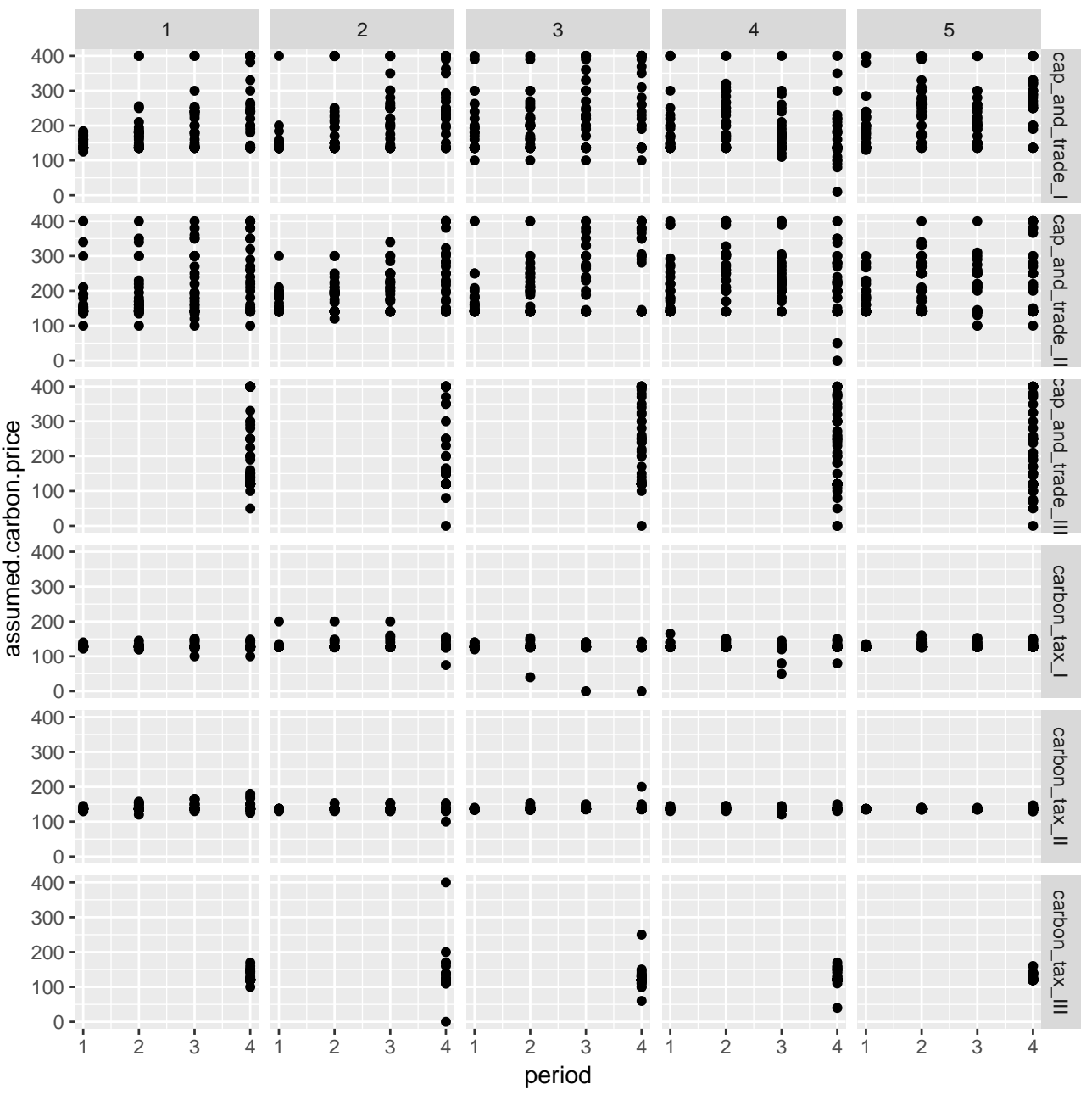

Note: Data for periods 1-3 was not recorded for the Cap III and Tax III treatments. 